\title{
The Global Energy Landscape and Materials Innovation
}

V.S. Arunachalam (Center for Study of Science, Technology \& Policy, India)

E.L. Fleischer (Materials Research Society, USA)

\section{Abstract}

Availability of affordable energy has enabled spectacular growth of industrialization and human development in all parts of the world. With growth now accelerating in developing countries, demands on energy sources and infrastructure are being stretched to new limits. Additional energy issues rity affected by the uneven distribution of energy resources around the globe Together these issues present a field of opportunity for innovations to address energy challenges throughout the world and all along the energy flow. These energy challenges form the backdrop for this special expanded issue of MRS Bulletin on Harnessing Materials for Energy. This article introduces the global landscape of materials issues associated with energy. It examines the complex web of energy availability, producthat lie at the core of these areas and discusses how revolutionary concepts can address them Cross-cutting topics are introduced and interrelationships between topics explored. Article topics are set in the context of the grand energy challenges that face the world into the middle of this century.

\section{Materials and Energy}

Energy and materials have a continual and mutually enriching relationship. Materials produce energy or enable energy to be transferred into useful forms. Energy, in turn, has made possible the production of a broad range of materials for society Materials for energy come in a near continuum: Naturally reactions. These are the fuels we extract from the ground, often burned to release their energy in the form of heat.

Then there are the engineered materials that tap externally available energy and transform it into useful forms. Photovoltaic silicon converts solar energy into electrical power. Wind turenergy into mechanical or electrical power. Materials also store and deliver energy - the batteries, wires and switches, hydrogen, and biofuels that convert energy from other forms

Materials then work to realize the ultimate objective of producing energy - its use. This might be tungsten filaments in turbine blades rotating in a jet engine. Materials thus have a synergistic relationship with energy, all the way from its generation to its ultimate use.

For the past few centuries, affordable energy, mainly from ossil fuels, has enabled industrialization and human developthe developing countries playing a major role in generating and consuming increasing amounts of energy. To support this growth, new resources have to be harnessed and existing one improved. Adding to these demands are the growing concerns about the sustainability of various energy sources and the chalsions left in their wake. There are also matters of energy security, with resources unevenly distributed around the world and nations vying for energy resources to support their growth
How can technology and materials research address these issues? This question forms the basis for this issue of $M R S$ Bulletin. Whereas the articles discuss the attractions and research challenges in specific energy areas, we are conscious
that all of these areas have to be seen in a broader context of developing options for generating and using energy efficiently, and pristinely. There are connection that can be built between technologies which can be useful in setting the agenda not only for research but also for focused
development. The scaling of some of the new technologies, and the emergence of innovations could eventually lead to the polluting energy giants.

Energy and Human Needs

The choice of materials for energy production has been dictated by the availability and accessibility of the source, its ecoand ral gas. Yet, coal remains an important fuel because of its continuing widespread availability and the large infrastructure for its conversion into useful forms of energy. Thus, there is no on unique global fuel for energy generation (Figure 1). Hererer the impact of energy in improving the quality of

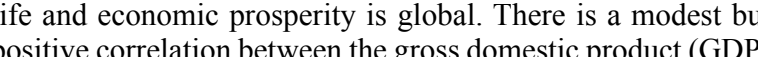
of a country and the amount of energy it consumes. Generally, developed countries consume more energy than developing countries, but over time, developed countries learn to produce and use energy far more efficiently, and the energy intensity

When a country is on the path of rapid growth, it needs far more energy per unit of growth than does a mature industrialized economy. ${ }^{2}$ Compared to China, India is yet to reach this
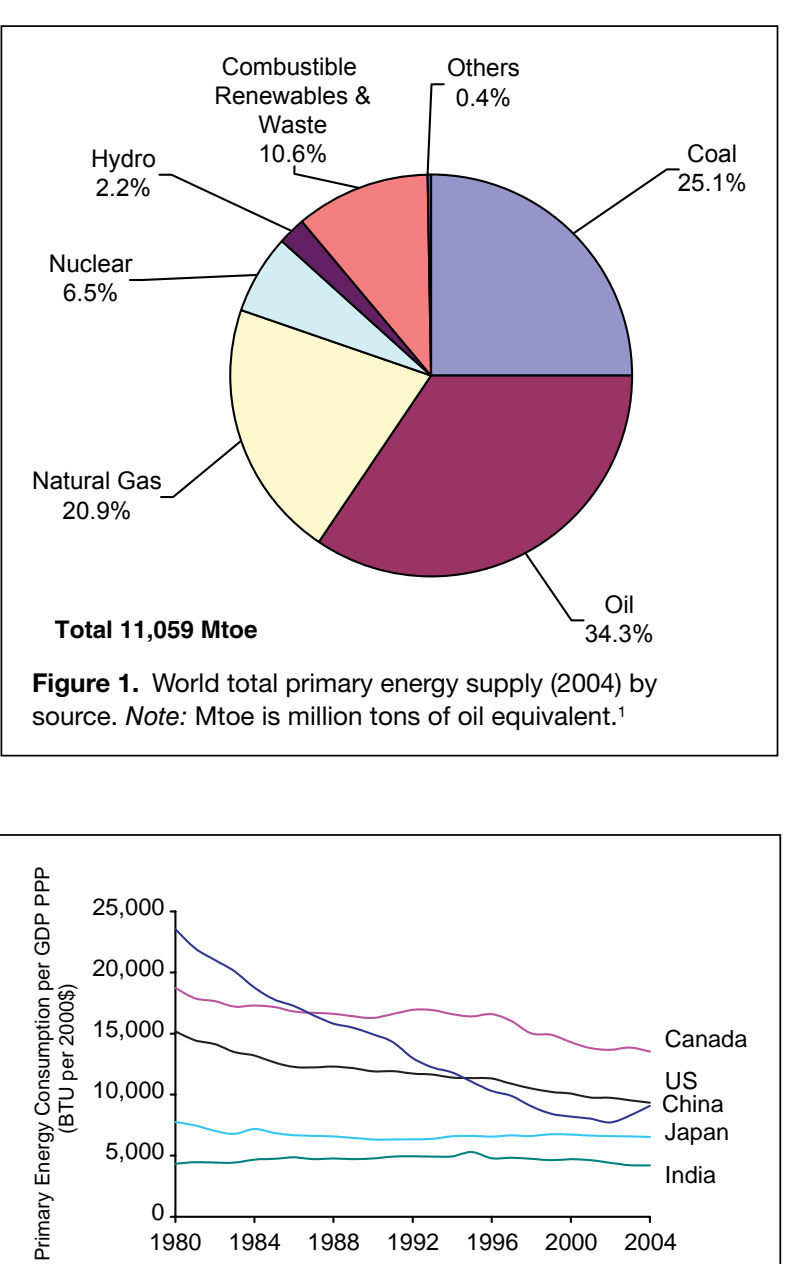

Figure 2. Total primary energy consumption per dollar of gross domestic product (GDP) (BTU per $2000 \$$ ) using
purchasing power parity (PPP).49

Although developed countries already have well-established Although developed corres for gen a energy challenges as they outgrow current energy infrastructures. The U.S. electrical transmission and distribution system, for example, has had an increase in the frequency and size of power outages in recent years

作 development index (HDI)-measuring income, education, and
health- with energy use (Figure 3). Norway, ranked 2nd in HDI, scores very high in both per capita annual electricity consumption $(26,657 \mathrm{kWh})$ and per capita GDP [PPP] (\$41,420). ${ }^{3}$ Ethiopia, ranked 169th in HDI, has a per capita GDP [PPP] of about $\$ 1,000$ and consumes a mere $36 \mathrm{kWh}$ per capita - equivalent to the conIndustrialization increases the demands for energy dramatically. The world's total primary energy consumption grew 20 times between 1850 and 2000 to the present value of about 15 Terawatt years per year.. ${ }^{4}$ Currently, industrialized countries consume a disproportionate share of energy compared to develmillion ( $4.8 \%$ of the world's population), consumes more than $21 \%$ of the world's energy production. India, with a population of one billion ( $16 \%$ of the world's population), consumes jus 3. on of of global energy generation. ${ }^{2}$ The article by Lave in this

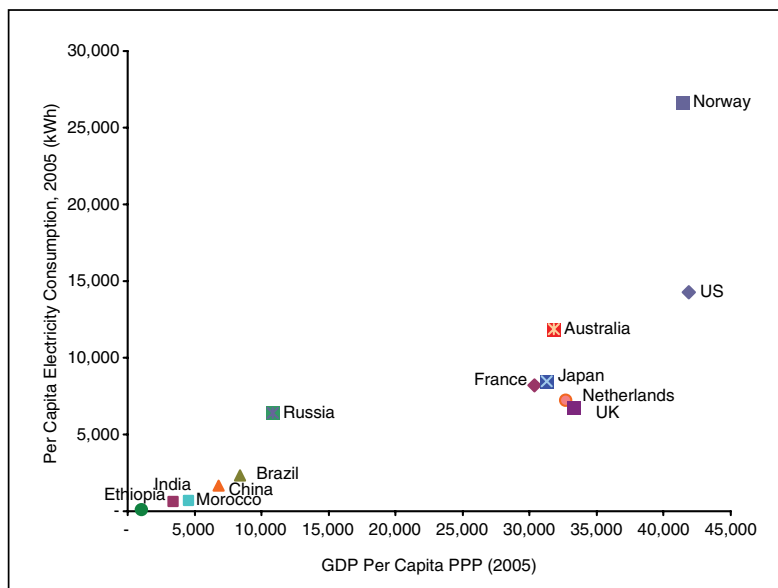

Figure 3. Per capita electricity consumption (kWh) versus GDP per capita purchasing power parity (PPP) of selected

issue explores the economics of energy and how economics, to the materials research challenges.

If all countries of the world were to enjoy the same level of prosperity as the developed nations, would the world run out of energy? Although one might argue that the world has enough energy sources to meet these needs-coal, at he present rate of such demands will deplete some energy sources rapidly and make others prohibitively costly. India and China having combined population of 2.4 billion account for only about $12 \%$ of world oil consumption. ${ }^{5}$ Personal car ownership in China is 9 per 1,000 ellgble drivers as compacd to 11 in hidia and 1,148 in the United States. ${ }^{6}$ However, China and India are likely to in the coming decades. ${ }^{5}$ The recent announcement by Tat Motors of India that they would soon be marketing a $\$ 2,500$ car is expected to boost India's automobile density significantly. If car ownership in India and China reaches half the present U.S level, then another 100 million barrels per day (BPD) will b BPD. ${ }^{6}$ This scenario describes the magnitude of just one of the many energy challenges the world faces. New discoveries an will be needed to meet such challenges.

Energy and Environment

All energy technologies leave an environmental footprint some more than others. Nuclear power, for instance, produces
both long-lived and short-term radioactive waste from which the public needs to be shielded. Even biofuels that are seen as benign can adversely affect the food and feed chains by diverting crops for energy generation. Large hydroelectric dams displace popula for tal concern relatest to the emission of greenhouse gases contributing
to global warming. All combusted fossil fuels emit $\mathrm{CO}_{2}$, a longlasting greenhouse gas that is not presently captured and removed from the stack emissions. There have been a number of scientific studies to estimate the extent of global warming. These studie suggest that a temperature rise of $0.6 \pm 0.2^{\circ} \mathrm{C}$ has already taken for Climate Change estimates a temperature increase of $1.8-40^{\circ} \mathrm{C}$ in the next century. ${ }^{\top}$ This, of course, depends on the climate model in the next century. This, of course, depends on the climate model
used and the assumptions made about global emissions over
the next century. Such temperature increases are likely to cause 
irreversible damage to life on Earth. For example, rising sea levels would pose serious risks for people living in coastal cities such a
London, New York, Mumbai, and Shanghai and a few low-lying countries. Because of such concerns, many countries, and eve some states and cities, have adopted regulations for limiting $\mathrm{CO}_{2}$ ing," giving benefits to industries with lower $\mathrm{CO}_{2}$ emissions and making higher emitting industries pay. Awareness is also growing among consumers to minimize their energy dependence by opting for energy-saving devices such as compact fluorescence bulb 作

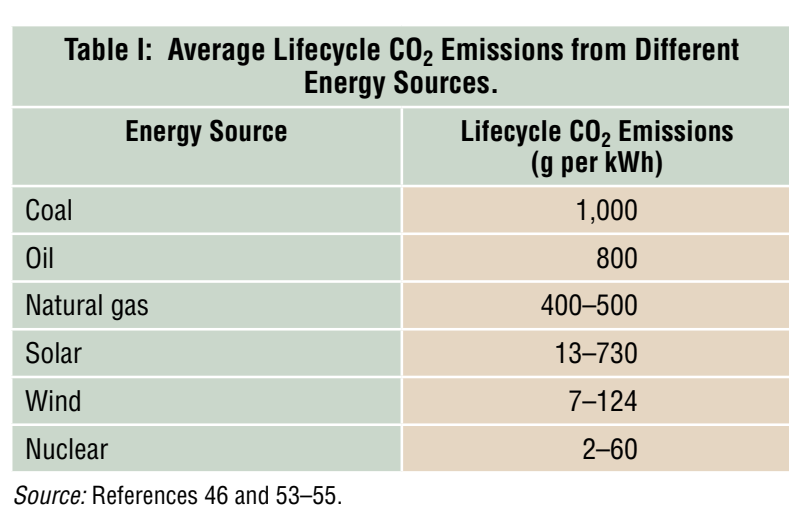

Reduction of $\mathrm{CO}_{2}$ in the atmosphere can be achieved by adopt作 underground in specially chosen geological formations or depleted oil wells. (See the article and sidebar by Benson and Orr in this issue.) It would also be desirable to artificially emulate nature

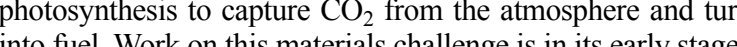

Energy Security

Some important sources of energy — such as oil, gas, an uranium - are not equitably distributed across continents. A heavy dependence for resources on just a few countries poses energy security issues. Price and supply volatility for oil and, have encouraged many countries to opt for harnessing domestic or dedicated resources. Brazil, for instance, has become the largest producer of ethanol from sugarcane as a fuel for vehicles. Similarly, Denmark is using wind power to generate $20 \%$ of it electricity and plans to increase wo pow to $50 \%$ by 2025. the needs of citizens and countries are met, another security risk relates to how spent nuclear waste is handled and the potentia for its use in developing nuclear weapons. The materials challenge here is one of developing safe long-term storage or finding ways to more efficiently use the nuclear materials to result

ntal, and security concern both locally and globally. The solutions nations pursue to satisfy their energy demands often have consequences that transcend their immediate needs and will require innovations

Energy Flows and Cycles

It is convenient to model the energy system as a directional flow with all possible energy resources flowing into it as tributar- ies. This flow then branches into distributaries as it is consumed in many ways. Along this path, energy is transformed into convenient
forms, stored where necessary and transported in time to the places of ultimate use. Throughout the process, some of the stream is lost as waste, and some is recycled. Energy tributaries - a few large
and some modest in size-come from biomass, coal oil gas sunlight, wind, water, and nuclear materials and are fed to their destinations by electrical grids, pipelines, railways, trucks, and ships. An energy flow diagram, when marked with appropriate data provides an integrated view of where the energy comes from, how it is used, and where energy is lost along the way. ${ }^{10} \mathrm{~A}$ conceptual vie Figure 4 shows two quantitative examples of energy flows, one fo the United States and one for India, highlighting the differences of these flows for a developed and a developing country. Biomass, for instance, continues to be a major fuel for primary energy generatio in India. What will be the consequences for energy security an greenhouse gas emissions when developing India opts for more effimodest consumption of gasoline in preference to diesel, as diesel has many applications from truck transport to standby power generation Agriculture in India consumes around $30 \%$ of electricity generation mainly for pumping underground water for irrigation. In this sector ment subsidies are difficult to monitor Can solar energy help? Wh might be the long-term consequences of underground reservo depletion? These energy flow diagrams enable us to locate such areas of concern and identify research opportunities to make a tributary contribute more to the energy flow and distributaries work to

Resources (Energy Tributaries)

The resource base for energy production is large and impressive. From biomass to nuclear fusion, the total energy availvarious fuel resources differ in their energy comption today. The various fuel resources differ in their energy content, prices, conTables II acd III sem availability, respectively, of variousenergy resources. Evidently, enough resources are available so that the world will not "ru out of energy."^ However, some of the fuels show high price

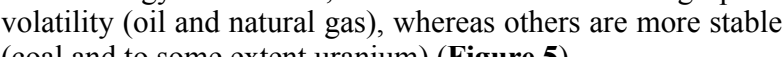

Table IV compares the cost of electric power generation from some of these resources. Still others are covered in the article by Sims in this issue. Some of the resources tend to be highly polluting, with coal, for example, emitting around $1 \mathrm{~kg}$
$(2.24 \mathrm{lb})$ of $\mathrm{CO}_{2}$ for every kilowatt-hour of power generate (Table I). There is also environmentally clean solar energy, but it has yet to realize its full potential.

It is convenient to divide the resources into three categorie: (1) those presently in use, (2) emerging technologies, and (3) long-term opportunities. In the first category, we consider

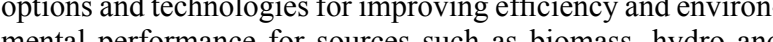
mental performance for sources such as biomass, hydro and category, which overlaps the first, are solar thermal and photovoltaics, wind power, nuclear breeder reactors, and biofuel. The third category includes harnessing the power of nucle fusion and extraction of methane hydrates from ocean beds, technologies that are yot to be filly explored Coal electric power generation. About $50 \%$ of the electricity in the Unite
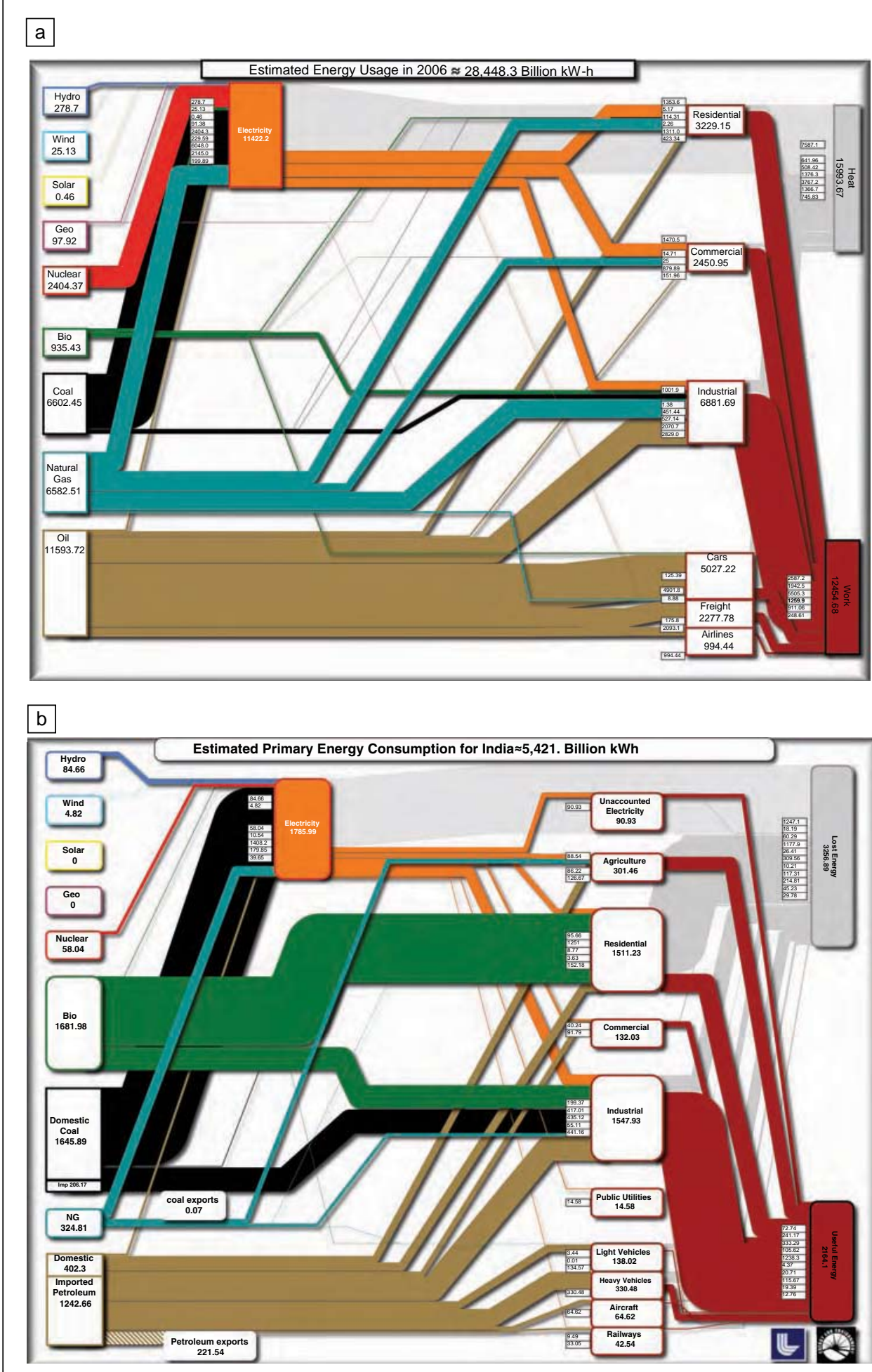

Figure 4. Energy flow diagrams (EFDs) for (a) the United States (2006) and (b) India (2004-2005) 10.50

Figure 4. Energy flow diagras
(Units: Billion kilowatt-hours)

States and $80 \%$ of that in China are generated from this resource. In 2006 alone, the use of coal increased by $4.5 \%$, and China contributed the maximum, around $8.7 \%$, of the total increase. "I The attractions of coal are many: It is cheap and widely
available, and the cost of power from it is low, at under 5 cents per kilowatt-hour $(\phi / k W h)$ lhovations in flue gas cleanu havts such as rapping of pollutcury, nitrogen oxides lates, merdioxide. However, $\mathrm{CO}_{2}$ emiss continue to be vented to the environment. Apart from injecting $\mathrm{CO}_{2}$ into the ground, as previously described, a few option $\mathrm{CO}_{2}$. These 0 otions include thecking up the $\mathrm{CO}_{2}$ by reacting with minerals such as basalt to produce carbonate minerals, although the kinetics for such reaction is expected to be slow and might not prove to be practiducted on the possibility of injecting carbonic acid deep into the oceanic sediments for the liquid to form clathrates. In suc struge of ice crystals that appears to settle down on the sea floor However, its long-term stability and impact on marine ecology are not known. Although thes options are being evaluated for
their technical and viability, the role of coal in a car-bon-constrained energy portfolio will also depend on the costs of $\mathrm{CO}_{2}$ sequestration. Cost calculasuggest that the price of electricity would increase by $50-100 \%$ stages were incorporated into new plant designs; ; a recen could be as low as $30 \%$ increase Table $\mathbf{V}$ shows how the Table $V$ shows how the capita
cost and cost of energy chan when sequestration stages are included in coal-fired power plants."l These costs should ence and learning.

Whereas the installation of $\mathrm{CO}_{2}$ sequestration systems in existing units is difficult and economically unattractive, it migh as an integrated unit instemly as an integrated unit in newly few technology options for designing new plants amenable for $\mathrm{CO}_{2}$ capture, including integrated gasification combinedcycle(IGCC)plantsandoxy grastion power plants. ${ }^{.1}$ The IGCC process involves gasifying coal to
combustible gas (syngas) consisting of a mixture of $\mathrm{CO}, \mathrm{H}_{2}$, $\mathrm{CO}_{2}, \mathrm{H}_{2} \mathrm{O}$, and other trace species. The syngas is combusted in a gas turbine, and the waste heat is used to power a steam genera- 
Table II: Higher Heating Values of Various Energy Resources.

\section{Resource \\ Higher Heating Value (MJ/kg)}

Hydrogen

Natural gas

Light diese

Gasoline

Ethanol

Methanol

Biomass (e.g., wood)

Coal

Source: References 11 and 56

Note: The higher heating value of a fuel is the amount of heat released (MJ)
through combustion from $1 \mathrm{~kg}$ of fuel source, assuming that the water released

\begin{tabular}{|c|c|}
\hline Resource & Enerav Potential (TWW) \\
\hline Oil and gas (conventional) & 1,000 \\
\hline Oil and gas (unconventional) & 2,000 \\
\hline Coal & 5,000 \\
\hline Methane clathrates & 20,000 \\
\hline Oil shale & 30,000 \\
\hline Uranium (conventional) & 370 \\
\hline Uranium (breeder) & 7,400 \\
\hline Sunlight on land & 30,000 per year \\
\hline Wind & 2,000 per year \\
\hline Fusion (if successful) & $250,000,000,000$ \\
\hline
\end{tabular}

Source: Reference 57 for uranium and Reference 4 for all other resources
Note: Current world energy use is about 15 TWy per year.

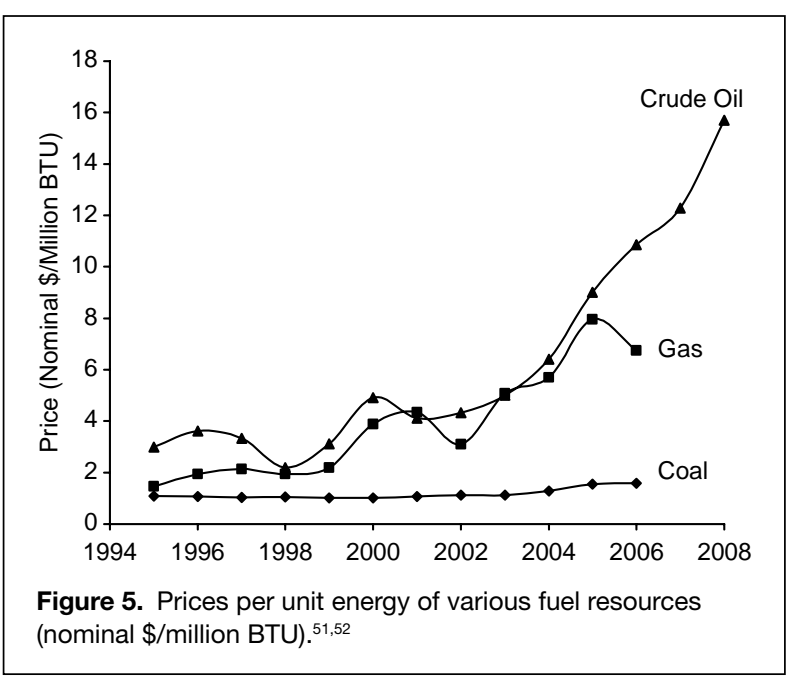

tor. IGCC power plants can operate at higher efficiencies (40Ultrasupercritical pulverized coal units use steam at high pressures and temperatures, leading to higher efficiencies of up to
$46 \% .{ }^{.1}$ These conditions would require development of oxida-

\begin{tabular}{|l|c|c|}
\hline \multicolumn{1}{|c|}{ Table IV: Costs of Electric Power from Several Sources. } \\
\hline \multicolumn{1}{|c|}{ Resource } & $\begin{array}{c}\text { Overnight } \\
\text { Construction } \\
(\mathbf{\$} / \mathbf{k W})\end{array}$ & $\begin{array}{c}\text { Levelized Cost of } \\
\text { Energy }(\boldsymbol{\epsilon} / \mathbf{k W h})\end{array}$ \\
\hline Coal & 1,300 & 4.2 \\
\hline Natural gas & 500 & 5.6 \\
\hline Nuclear & 2,000 & 6.7 \\
\hline
\end{tabular}

Source: Reference 29

Table V: Costs and Efficiencies of Coal Power Plants with and

Energy Source Capital Cost Cost of Energy EEfficiency

\begin{tabular}{|l|c|c|c|}
\hline Coal (subcritical) & $\$ 1,280$ & 4.84 & $\begin{array}{c}\text { Malue) } \\
\text { Valuting }\end{array}$ \\
\hline
\end{tabular}

\begin{tabular}{|l|l|l|l|}
\hline Coal with CCS & $\$ 2,230$ & 8.84 & $34.3 \%$ \\
\hline
\end{tabular}

(subcritical)

\begin{tabular}{|l|l|l|l|}
\hline Coal & $\$ 1,330$ & 4.78 & $38.5 \%$ \\
\hline
\end{tabular}

\begin{tabular}{|c|c|c|c|}
\hline Coal with CCS & $\$ 2,140$ & 7.69 & $29.3 \%$ \\
\hline
\end{tabular}

Source: Reference 11 .
Note: CCS, carbon capture and sequestration; subcritical, operating at steam
temperatures and pressures below the critical point (generally at $5400^{\circ} \mathrm{C}$ and

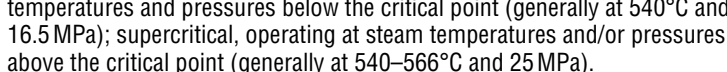

tion- and corrosion-resistant high-temperature materials for ga turbines. See the article by Powell and Morreale in this issue o coal combustion technologies for an in-depth look at the materials and processes associated with cool.
Also being studied is underground gasification, where the coal seams themselves would form in situ gasifiers expelling carbon monoxide and hydrogen (syngas) used in a gas turbine. Preliminary economic analysis suggests that carrying out gas-
ification underground could prove to be more economical the ification underground could prove to be more economical than
building gasifiers above ground. The environmental consequences of underground gasification require further analysis. Coal gasifiers can also be integrated with high-temperature,
ceramic-based, solid-oxide fuel cells. These fuel cells can utceramic-based, solid-oxide fuel cells. These fuel cells can utilize the syngas directly from the gasifier. Details of these processes and the materials challenges involved both in building cussed in the article by Crabtree and Dresselhaus in this isse.

Oil/Gas to Biofuels

Oil industry professionals use a construct known as Hubbert's peak to estimate the amount of recoverable oil from know reserves. This construct is based on the observation that the rate
of extraction from a finite source peaks when half of the oil reserves have been exploited, and then the extraction declines to uneconomical levels. ${ }^{14}$ Based on known reserves, it has been estimated both that the peak for world production of oil should have already occurred ${ }^{15}$ and that it will not occur in the near
future. ${ }^{16}$ In either scenario, without new oil discoveries or meth ods of extraction, oil production would start to decline after the peak has been reached. There is even less unanimity on when world oil production will reach its peak when new discoveries of accessible oil are included in the discussion: Saudi Arabia reports no end in sight for at least 60 more years. The recent BP Statistical Review of World Energy quotes the proven reservesto-production ratio to be 40.5 years, with the reserves estimated to be over one trillion barrels. ${ }^{\prime \prime}$ Regardless, the rate of use of oil consumption continues to grow, with nations vying with one
another to sign agreements for guaranteed supply. The world consumption has grown to 83 million barrels per day from 48 million barrels per day in $1970 .{ }^{18} \mathrm{~A}$ recent report by the National Petroleum Council addressed some of the "hard truths" facing the oil and gas industry this century, and these findings are addressed in the article by Holditch and Chianelli in this issue. Natural gas entered as an attractive alternative fuel and has ral gas has come down significantly in recent years, and transportation of liquefied natural gas aboard large ocean-going tankers has extended the availability of natural gas beyond the limits of pipelines. The $\mathrm{CO}_{2}$ emission is low (about 500 grams per $\mathrm{kWh}$ as compared to 1,000 grams per $\mathrm{kWh}$ for coal), and ent rate of consumption. ${ }^{17}$ The Russian Federation is the largest producer and also the largest consumer of natural gas. As in the case of oil, the Middle East has large reservoirs of natural gas. When the price of natural gas was low, many countries chose it resource increased, so did its price.

If the oil extracted from conventional wells becomes scarce
resource increased so dits pre. and costly, are there other options? Canadian and Venezuelan oil-containing sands are seen as potential substitutes. Oil sands contain clay, sand, water, and bitumen (a very heavy condensate of oil), and the Canadian reserves alone are estimated to contain
around 175 billion barrels of oil.19 Because of the low concentration of hydrocarbons, the extraction processes are more involved, including mining of the sands and technologies for stripping bitumen from them and refining the heavy oil. The environmental sustainability of such extraction processes has been questioned because of the demands made on water, energy appropriate structural malabls that high temperatures can also be an issue.

Yet another stash of fossil fuel deposits is described by Rath, in a sidebar to the article on oil and gas in this issue. Methane line most of thentially ice-like cages with methane trapped insideand permafrost regions. Estimates suggest that this resource exceeds twice the gmount of all other recoverable and nonrecoverable fossil fuels. However, the risks, benefits, and methods of extracting these deposits are still being weighed, so this resource is not ready to contribute to energy needs in the near future.

There is also the option to produce liquid fuel from coal,
using Fischer-Tropsch (FT) synthesis. This process inoles using Fischer-Tropsch (FT) synthesis. This process involves Using the water-gas shift reaction to adjust the ratio between $\mathrm{CO}$ and $\mathrm{H}_{2}$ in the syngas to desired levels and using appropriate FT catalysts, synthetic fuels (popularly known as synfuels) ranging from light hydrocarbons to waxes can be produced. However, the process of making liquid fuels involves $\mathrm{CO}_{2}$ of liquid fuels from coal emits about $50 \%$ more $\mathrm{CO}_{2}$ than use of conventional gasoline or diesel. ${ }^{11}$ The advantage of FT synthesis for some countries appears to be the ability to use a plentiful, locally available raw material (coal) to produce liquid China is known to be building two plants with South African collaboration, each with a capacity of over 80,000 barrels a day. If India and China opt for this route, $\mathrm{CO}_{2}$ emissions from the two countries would increase significantly.
Are there alternate strategies for replacing fossil fuels using sustainable sources without $\mathrm{CO}_{2}$ penalties? Many countries are agricultural produce and wastes, as described in the article on ell and Gopal in this issue.

Brazil has been the first country to commercially produce harge amounts of ethanol from its sugarcane harvests as a substitute for gasoline. Various grades of fuel ranging from $5 \%$ ethano gasolne to nearly $100 \%$ ethanol are now in production and

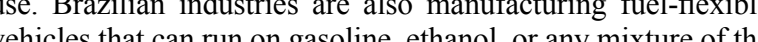
vehicles that can run on gasoline, ethanol, or any mixture of the in the automobile engine, engines resistant to such deterioration have been produced. Whereas Brazil is producing ethanol from sugarcane where the ratio of energy output to input is greater than five, this ratio for ethanol produced in the United States from corn is more modest at $1.34,{ }^{20}$ for net energy production o ability of diverting produce now used for human consemption and animal feed from the food chain to ethanol production. Fo example, there have been reports about the escalating cost of corn and scarcity of soybean planting, which was abandone because of the attractive marketability of corn for ethanol. Also result, depending on the type of vegetation that the biofuel crops replace 22,23 However, the real race for plant-based ethanol is in developing an economically viable and socially sustainable route for producing it from cellulose (see the sidebar by Wyman in this issue). If successful, the energy payback can be as high as 14:1
Several technological pathways are available, some of which are shown in Figure 6. ${ }^{24} \mathrm{~A}$ few large-scale experiments on the production of cellulosic ethanol have been reported. ${ }^{25,26}$ These developments are of increasing interest because such processe would not interfere with the food chain and the energy inputs for cultivation would be minimal. Moving toward even greater article, discuss engineered and artificial photosynthesis to leam from and enhance what Nature creates.

Meanwhile, a number of initiatives to use the fruits of oilbearing plants to produce biodiesel have been launched. Jatropha, a hardy plant that grows wild in many parts of the required to grow this plant is not large, nor is this crop inpu the food chain. Detailed economic analysis of the manufacturing of jatropha-derived diesel is not yet available. Even though the acreage required for cultivating jatropha is large- - for India, it would be the third largest after rice and wheat - it has bee suggested th

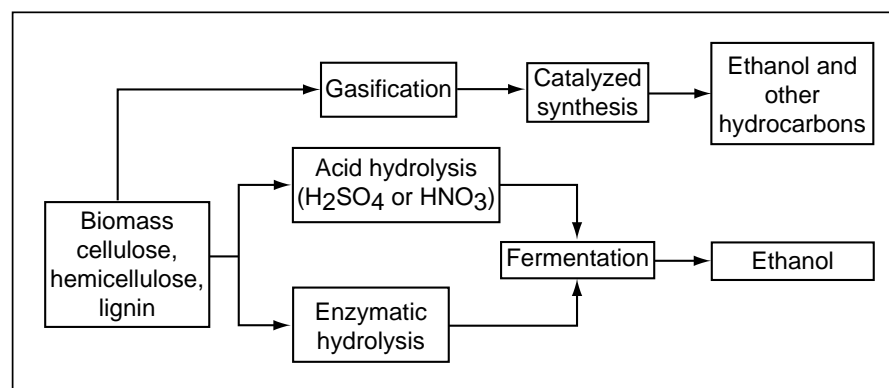

Figure 6. Con
feedstock. ${ }^{24}$ 
Nuclear Power

After many years, nuclear power is re-emerging from the shadows in the United States, whereas France already obtain Nuclear power reactors do not emit $\mathrm{CO}_{2}$, and the entire nuclear cycle has a modest $\mathrm{CO}_{2}$ footprint Although fers still linger nuea the Three Mile Island (1979) and Chernobyl (1986) accidents, the safety record and energy production of nuclear power plants since that time provide a new perspective. Worldwide, 443 powe reactors with an installed capacity of $370 \mathrm{GW}$ of electrical power have produced over 2,600 billion $\mathrm{kWh}$ annually without a majo accident in over 20 years. ${ }^{20}$ However, reactor safety is still an concerning nuclear waste disposal and prevention of nuclear weapons proliferation. Cost is also an issue. Nuclear power stations tend to be at least $15-30 \%$ costlier than conventional coal Nion and are also capital intensive.

Nevertheless, of global energy needs in the coming decades, until the world fully realizes the potential of other low-CO $\mathrm{CO}_{2}$-emitting energy sources. The world uranium reserves are estimated to be 4.7 million tons. At the current annual rate of use, the presen proven resources are adequate for over 85 years of operation. ${ }^{30}$
If the capacity is increased to $530 \mathrm{GW}$ electrical, the annu consumption of uranium would be 100,000 tons, adequate for about 40 years.

Materials options can help extend the service life of presently operating reactors. Most of the nondestructive testing technologies specially developed for examining the integrity of
structural components suggest that the lifetimes of the presently operating nuclear reactors (specifically light water reactors) can be extended by about 20 years. Economists estimate that this extension of service life alone is equivalent to $40 \%$ of the cost of building a new reactor. ${ }^{31}$ The lessons learned from the life extension exercise suggest that, for newly designed light water and its components could be compositionally tailared to core high temperatures and radiation levels without failure. Components that are more tolerant to radiation will reduce degradation, allowing the reactors to operate up to a burn-up of
over 100,000 megawatt-days per ton of uranium fuel, ${ }^{29}$ almost over 100,000 megawatt-days
double that of current reactors. Furthermore, there are ways to extend the useful energy
extracted from nuclear materials. Light water reactors and pressurized heavy water reactors use natural uranium or slightly enriched uranium containing about $4 \%$ of the ${ }^{235} \mathrm{U}$ isotope as the fuel. In natural uranium, the isotopic content of $233 \mathrm{U}$ is $\sim 0.7 \%$. The rost of his during irradiation in the reactor,
which is fissionable and can be used as a a fuel. In the open-cycle system, the spent fuel is not reprocessed to extract plutonium.
Instead, it is treated as nuclear waste and safe-guarded. In the Instead, it is treated as nuclear waste and safe-guarded. In the closed-cycle system, the spent fuel is reprocessed to extract plu-
tonium which can amount to a few kilograms for every ton of spent fuel. The plutonium can be used as the fuel for enriching itself. In highly enriched fuel, it is possible to transform more ${ }^{235} \mathrm{U}$ into plutonium and thus "breed" more plutonium in the reactor. Such reactors, known as breeders, can also be designed to produce $23 \mathrm{U}$-another fissionable isotope of uranium--from the naturally occurring element thorium; this approach is under this issue by Raj et al. for more information on nuclear power. A prototype fast breeder of $500 \mathrm{MW}$ capacity is presently
andruction in India. Breeder reactors offer opportuni- ties for extending the fuel resource base by at least a factor of 60. However, some major concerns arise in terms of reprocesing the spent fuel. Plutonium is an ideal material for nuclea weapons, and reprocessing of the spent fuel could make this 作 Hecker in a sidebar to the article on nuclear power in this issue. The other major concern about the safe handling of nuclear wastes is discussed in the sidebar by Ewing.

For nuclear power without the issues regarding radioactive uranium and plutonium, one can turn to nuclear fusion. In releasing a large amount of energy. The ITER project, which is an international program to demonstrate the scientific and tectnological feasibility of fusion energy, is a next step toward determining the materials that would be needed to contain such a reaction, alhough results from this project are not expected

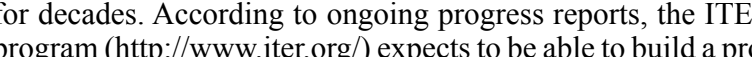
totype fusion power plant of 1.5 gigawatts electrical, based on magnetic confinement of plasma by about 2050 . The economics might prove to be the determining factor in choosing nuclear power. Recent studies have suggested that, become ing $\mathrm{CO}_{2}$ emissions. ${ }^{2}{ }^{2}$ In addition to accounting for $\mathrm{CO}_{2}$ reductio and decommissioning costs, the economic analysis would also have to account for the risks and uncertainties associated with nuclear waste and the potential for nuclear weapons proliferation. Solar

Unlike other resources, solar energy is almost limitless. Several parts of Earth receive good solar radiation of abou 600-800 watts/square meter. An hour of solar radiation on Earth provides 14 terawat-years of energy, almost the same as is nonpolluting annual energy consumption. . $^{3,34}$ Solar energy easy to capture the solar radiation and store the energy efficiently, there would be no global scarcity of renewable and clean energy. Presently, solar collection contributes only a tiny (t) per year, led in paticular by Germany a Ginley, Green, and Collins in this issue focuses broadly on range of solar developments.

There are two routes for solar energy generation: solar thermal and solar photovoltaics. In the solar thermal approach, the sun's radiation is converted to heat that is either used directly, more commonly as concentrating solar power (CSP). In CS technologies, the heat is used to operate a steam generator to produce electricity. In solar photovoltaics, semiconductors are used to convert solar radiation into electric energy, which can
be either used locally in autonomous systems or connected to be either used locally

The efficiency of CSP plants can be around $15-20 \%$, but the installation and generation costs are high, almost five times those of coal..$^{35}$ To generate about 12 terawatt-years of energy, large land areas are needed, around 50-75 million hectares. More information on CSP can be found in the sidebar by Mehos energen industrial processes can also be used to generate thermoelectric energy. Thermoelectric materials are covered by Tritt, Böttne and Chen in another sidebar in this issue. The specifications for solar photovoltaics developments are
multifold. The cells have to be efficient and stable, and the cost of manufacturing should be competitive. Semiconductor photovoltaics are showing recent impressive efficiency gains. The first generation of solar sells based on single-crystalline silicon (CdTe) can attain even higher efficiencies, around $20 \%$. Multijunction thin films, with several layers matched to capture different wavelengths of light, can chieve $40 \%$ conversion efficiency. ${ }^{3}$.

The solar cell family includes thin films, amorphous structures, and polycrystalline materials, each providing its own
advantages either in cost or in the efficiency of conversion. Furthermore, quantum-dot structures with very high efficiencies approach theoretical limits. Organic photovoltaics, on the other hand, compensate for their low efficiencies with the promise of lower manufacturing costs.

Although the performance of solar power is impressive, its costs continue to be daunting: an average of $\$ 0.25$ per kilowattFigure 7 compares the costs and performance of solar energy to those of biofuels and wind from the same land mass. ${ }^{39}$ The U.S. Department of Energy specifies that the initial capital cost to the end user of grid-tied photovoltaic systems
should be reduced to $\$ 3.30$ per peak watt from $\$ 6.25$ per peak watt in $2000{ }^{38}$ Another requirement has to do with toxicity conmodules. The use of CdTe, which can be toxic at high levels of ung exposure, is a case in point.

To make photovoltaics affordable, it is necessary to bring and thin films that can be grown into long a morphous ribbons, amenable to large-scale production.

A major competitor to inorganic photovoltaics is the emergence of organic-based photovoltaics, which have very different operating mechis. Excitons - closely bound electron-hole pairs-are first generated and then decomposed into free charge be kept very thin because of the low mobility of charge carriers.

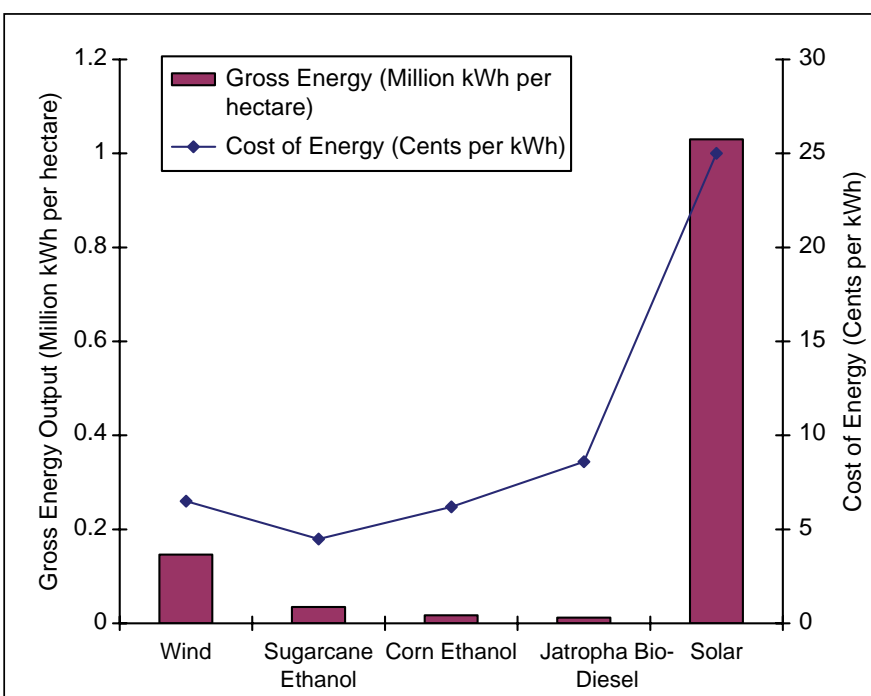

Figure 7. Gross energy output (million $\mathrm{kWh}$ per hectare) and cost (cents per $k$ Wh) of resource produced from 1 hectare of land for severa renewable sources of energyy ${ }^{39}$ In the case of wind and solar,
resource is electricity, whereas in other cases, it is the energy resource is electricity,
contained in biofuel.
A few new schemes attempt to solve some of the intrinsic deficiencies of organic photovoltaics and include the incorporation sectrum, organic-inorganic composites, and nanocomposite that help add more charge carriers. Even though some of the in tial problems, such as rapid degradation of performance, have remain to be addressed. The efficiency has to be improved to better than the $5 \%$ presently obtained in laboratories, the operaing lifetime has to be raised without degradation of performance, and the manufacturing of polymers containing mixtures of inorcheaply at a large scale. Considering the speed with which liquid crystal displays (LCDs) are replacing conventional displays
(some have predicted that LCDs will soon become as cheap as acrylic paints used for painting homes), organic semiconductor are ripe for becoming a similarly disruptive technology.
Because of the cyclical nature of solar radiation it is

to install ade of he cyclical nature dis solar radiation, it is necessary In an earlier article in MRS Bulletin, Smalley recommended distributed storage systems to provide for base-load needs. ${ }^{40}$ The attractions of sustainability and clean energy without any greenhouse gas emissions make solar energy a compelling option. lowering costs, and developing novel materials, diverse regions bar by Palucka covers the California Solar Initiative, a $\$ 3.3$ billion program to generate $3 \mathrm{GW}$ of electricity by 2017 by encouraging solar cell installations on the roofs of residentia and commercial buildings. Soboyejo and Taylor, in a sideba
about off-grid solar power, focus instead on the two billio people on the planet who do not have reliable electric services. They describe how simple solar-electric systems can help some of the rural populations in Africa, Latin America, Asia,

Wind Energy

In contrast to solar power, wind power is a mature technology wind energy generation at locations with wind speeds in exces of $6.9 \mathrm{~m} / \mathrm{s}$ at $80 \mathrm{~m}$ above ground is estimated to be around 72 terwher prevent its full potential from being tapped. ${ }^{42}$ Because of its dependence on wind speed the locations where wind power generators can be installed are limited. Although there have been impressive innovations in control engineering in directing the
fans toward the wind direction and even altering the pitch of the blades to suit wind speeds, the limiting factors of this energy resource are inherent to he nature of whi power itself, namely, eration. The efficiency of wind power is about $20 \%$. Off-shor turbines are an option, but they might prove to be expensive
because of the challenges of accessing these locations and the harsh environments that must be tolerated.

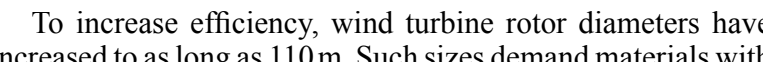
stable mechanical and environmental properties. Composites such as fiber-reinforced plastics and foam structures are now the mainstay. Carbon composites have also become popula because of their availability - made possible as a result of their enceds of win energy turbines are different from aerospace requirements. The
blades have to be stiff to prevent excessive deflection and strong to prevent buckling failure. Fatigue can become a major prob-
lem because of alternating stress due to rotation. The article by 

Hayman, Wedel-Heinen, and Brøndsted in this issue discusses
the materials issues related to wind power.

Carriers, Storage, and Transformations ydrogen as a Fuel?

ee hydrog, calling hydrogen a source of energy is wrong, as derived from other primary energy sources. Instead, it should be seen as an energy carrier just like electricity. Unlike electric power, however, hydrogen can be stored, though not yet at high energy density. Despite these limitations, the use of hydrogen as a prime mover is being pursued in laboratories and pilot
experiments, because hydrogen, once produced, is a clean fuel and its use is nonpolluting. Its energy content on a weight basis is almost triple that of natural gas. It is also an ideal fuel for fuel cells, which can, under many conditions, generate electric
power more efficiently than a combined-cycle gas turbine. ${ }^{43}$ power more efficiently than a combined-cycle gas turbine.
The challenges, then, are to generate hydrogen efficiently with minimum $\mathrm{CO}_{2}$ emissions and to store it efficiently. The dewity of hydrogen is so low that, even in its liquid state, its volumetric energy density is one-third that of gasoline. The use of hydrogen as a fuel for transportation would require technologies that can store enough hydrogen to provide power for a distance of either as a liquid (although $30-40 \%$ of its energy is sacrificed in liquefying it) or as complex metal hydrides that would be able to store the gas with a volumetric density of $81 \mathrm{~kg} / \mathrm{m}^{3}$ and release it efficiently near $70-100^{\circ} \mathrm{C}$. Such storage materials would also need to be recyclable and to have rapid kinetics for hydrogen release and absorption. Presently, no chemical co
pounds have emerged that meet all of these conditions. Crabtree and Dresselhaus in an article in this issue, esting that the world hydrogen production will have to increase from the present 60 million tons to 600 million tons to power the global fleet of cars and light trucks by 2030 . Where would we get this hydrogen? Because hydrogen is not a primary energy
source, it has to be produced from other sources such as coal source, it has to be produced from other sources such as coal, meaning that the hydrogen production process would involve $\mathrm{CO}_{2}$ emissions. Steam reforming of natural gas is a commercially available technology and accounts for the bulk of hydrogen production today. Our estimates based on results in natural gas would be required to of hydrogen. Present world production of natural gas is about 2,100 million tons, and thus, this process would double the demand for natural gas. This process would also involve about 5,000 million tons of $\mathrm{CO}_{2}$ emissions, which would have to be captured and sequestered. One potential advantage of this
option, though, is that $\mathrm{CO}_{2}$ emissions are concentrated the source and hence more amenable for capture.

Coal gasification followed by the water-gas shift reaction is another technology option for hydrogen production. We estimate that it would require about 4,500 million tons of coal to produce 600 million tons of hydrogen based on results in
References 45 and 46 . Present world coal production is 6,400 million tons. This process is more carbon intediction is 6,400 of natural gas; $\mathrm{CO}_{2}$ emissions would be in excess of 10,00015,000 million tons and would have to be sequestered. Extracting hydrogen from water is theoretically the "heart" of the hydrogen economy. Water molecules could be split to to produce electric power at high efficiency, emitting pure water.
However, electricity for splitting water molecules must come from renewable sources, or it will be coming from the very fossil
fuels that hydrogen aims to replace. About 31,000 billion $\mathrm{kWh}$ of electricity would be required to produce 600 million tons of
hydrogen from water. Present world electricity generation is about 18,000 billion $\mathrm{kWh}$, and electricity from renewable sources is a mere 370 billion $\mathrm{kWh}$. Clearly, renewable sources are nowhere near the level required to make the required amount
of hydrogen. Both major innovations for generating hydrogen it are needed before hydrogen can substitute for fossil fuels.

Fuel Cells

Hydrogen as a fuel or carrier of energy is never discussed high efficiency of about $50-60 \%$ and low emissions. They are modular and can be distributed. They cause no noise pollution. But they are expensive. For fuel cells to become competitive the cost must be reduced to the same level as that of an interna combustion engine, taking into account the cost of fuel and the hydrogen takes place at the anode thereby liberatidation of hydrogen takes place at the anode, thereby liberating protons cathode and participate in the electro-reduction of oxygen. Electric power generation results from the flow of electron through an outside circuit. Electrolytes are available throug ions are mobile, giving rise to different types of fuel cells. Fued cells are complex because of the restrictions imposed on materials, that is, the electrodes and electrolytes used and the design. A number of auxiliary components are needed such as systems for gas purification to eliminate $\mathrm{CO}$ and $\mathrm{CO}_{2}$, pressurization, and cooling. Often, it is an auxiliary component, an
not the fuel cell itself that fails. However recent breakthrough in both electrolyte and electrode materials for solid electrolyte systems are envisioned to greatly simplify fuel cell design.
Solid-oxide fuel cells are reliable for continuous operation. Although they have to be operated at high temperatures, aroun

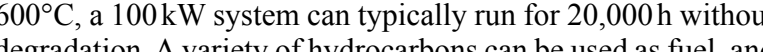
degradation. A variety of hydrocarbons can be used as fuel, an The other candidate electrolyte materials are doped ceria, doped lanthanum gallate, and doped barium zirconate. Current research focuses on direct electrochemical oxidation of fuels a andes, where the hydrocarbon fuels react directly with oxygen Electrolytes are being replaced with solid acids with properties intermediate between those of normal acids and normal salts. Research on materials for solid-oxide fuel cells and polymer electrolyte membrane fuel cells are expected to result in simple designs and more reliable operation. Large-scale deployment of

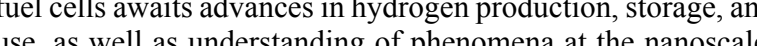
use, as well as understanding of phenomena at the nanoscale.
The growth of the fuel cell industry will depend on how efficient and robust the cells become and how the scale of production brings down the cost.

Energy Storage and Flow

from its source to where it is needed id fuels, transportation occurs by means of pipelines, trucks, and other carriers. In the case of electricity,
movement occurs through the electrical grid. For renewable sources, storage systems are needed to convey the energy produced to the grid and for use in mobile electronics. in each case, there are losses along the way. The collective electrical transthey vary from country to country. There are losses in the case of petroleum and natural gas due to spills and leakage, with environmental consequences. In all cases, conversion of matter to facilitate transport or storage adds further to the inefficiencies of getting energy from source to use.

Wurce the increase in demand for electricity and multiple versatile. In their article in this issue, Amin and Strings become the concept of a smart, self-healing grid that quickly senses and switches the flow as needed. Such a system would identify surges, downed lines, and outages; control damage instantaneously; balance loads reliably and dynamically; and be less vulnerable to terrorist attack. Although upgrading the grid to digital technology will have the most significant effect, materials are importan enablers. Nanomaterials for small but sensitive sensors, piezo-
electric materials that respond to electrical signals, and semiconductors that can endure high powers and high temperatures are
entering the mix, bringing strength and agility to the grid. The future might hold opportunities for wires strengthened with carbon nanotubes, superconducting wires with no losses, or systems
in space to capture and beam energy back to Earth. Additionally, the concept of micropower sources, for example, salvaging
energy from the environment for self-sufficient wirleless sensor nodes and networks, have a role, which is considered in the sidebar by Steingart, Roundy, Wright, and Evans.

Although electricity is a versatile transporter, it cannot be trical energy and carry bits of it away from the outlet, but their capacity and power is insufficient for handling the demands of large power generators. Remarkably, one of the most costeffective ways to store large amounts of energy is to use it to pump water uphill, recovering as much as $75 \%$ of the energy as hydropower as it later flows downhill. However, this option is

Battery technology has progressed through lead acid and
nickel-cadmium systems to nickel-metal hydride batteries, nickel-cadmium systems, to nickel-metal hydride batteries,
and now to lithium-based systems and systems based on nanomaterials. (See the article by Whittingham in this issue.) Sodium-sulfur systems are being used for large-scale applications, and supercapacitors are beginning to find a role when
high power is involved. Whether for portable applications such as cells phones and hybrid cars or for static applications such as backup systems, load leveling, and storing energy generated by alternative energy devices, the growing demands on energy storage require leaps in storage capacity and power output, as
well as reductions in cost paralleling Moore's law in the semiconducing ind conducting industry that has guided rapid doubling of comput-
ing power for many decades. Recent progress in batteries includes development of compounds with crystal structures that promote Li ion mobility, use of silicon nanowire anodes that can contain higher amounts of $\mathrm{Li}$ without breaking during silicon nons is used as an electrode. The corlos which silicon nanograss is used as an electrode. The contact angle of
a liquid on the nanograss is modified so as to isolate the liquid electrolyte, and electrochemical reactions do not take place until power is actually needed.

Catalysts

In addition to the flow and storage of energy, reactions and source, carrier, or user of energy, catalysts play an importan role in facilitating the transformation of materials. From the refining of oil and breakdown of cellulose to the liquefaction of coal and operation of fuel cells, this unique brand of materials com view. By opening new rectiow phe from view. By opening new reaction pathways and forming
intermediary compounds in a chemical dance, catalysts speed reactions by orders of magnitude, lower energy barriers, an increase efficiency. They take many forms, such as porous materials and oxides, and face challenges of their own. The particularly as applied to oil and biofuels. The table in that artcle lists the catalysts used in petroleum refining, sulfur an nitrogen removal, the water-gas shift reaction, and methano
synthesis, for example. The recent approach of modifying the subsurface of a platinum catalyst while retaining the platinum skin holds much promise. In the solar route to splitting water to produce hydrogen, a few photocatalysts are under scrutiny There is also the possibility of catalytic conversion of $\mathrm{CO}_{2}-$ Energy Use and Efficiency

In earlier sections, we focused on energy generation an distribution, the so-called supply side. There is also another dimension for increasing the availability of energy, namely, the demand side. Here, achieving efficiency in delivery and con-
sumption is the imperative. Judkoff, in his article in this issue sumption is the imperative. Judkofl, in his article in this issue that uses $65 \%$ less energy than other buildings under equivalent building codes; it saves energy through a range of feature including photovoltaics, passive heating, and sensors. Likewise Kusakabe, in a sidebar to the buildings article, describes power system that reduced $\mathrm{CO}_{2}$ emissions significantly. tists in seeking low-environmental-impact alternatives to the raw materials for construction.

The majority of innovations for improving efficiency tend to be incremental, but there are a few exceptions. For instance,
high-strength low-alloy steels can substitute for heavy steel in automobiles. A more radical innovation involves heavy steel automotive bodies with the frames, which reduces the weight of the vehicles significantly and thus saves energy. ${ }^{47}$ The article in this issue by Carpenter et al. on road transportation explore Redweight materials for power tains, hybrids, and tires. Reducing the weight of materials while maintaining strengt bar to the transportation article by Banerjee focuses on the unique materials needs in aviation.

The hybrid engine is an outstanding example of radica innovation. Here, the electric motor, under certain driving conimproves energy efficiency by charging the battery with the energy dissipated during braking. More importantly, $\mathrm{CO}_{2}$ emis sions are reduced when the electric motor takes over. With allelectric automobiles, now under development and in use in
small numbers, no $\mathrm{CO}_{2}$ is emitted during driving, although total small numbers, no $\mathrm{CO}_{2}$ is emitted during driving, although total
$\mathrm{CO}_{2}$ emissions depend on the electricity source. Even if energy $\mathrm{CO}_{2}$ emissions depend on the electricity source. Even if energy
from coal-fired power stations were used for charging, the $\mathrm{CO}_{2}$ production would be shifted from tailpipes to large generating stations, which would facilitate carbon capture and sequestration by centralizing the $\mathrm{CO}_{2}$ emissions. However, the benefit of this approach would be dependent on the ability to achieve
such capture. Large-scale substitution of hydrogen for gasoline such capture. Large-scale substitution of hydrogen for gasoline
and fuel cells for internal combustion engines will have to wait for the development of efficient storage and distribution systems for hydrogen. Fuel

Another case ripe for substitution is the switch from
and incandescent light bulbs with more efficient light sources such . $20 \%$ of generated energy in many countries. Tungsten filament
bulbs continue to be fragile, with a lifetime of a mere $1,000 \mathrm{~h}$ and an efficiency of $5 \%$. Compact florescence lamps have an
efficiency of over $15 \%$, but contain mercury. LEDs have 
efficiencies of $30 \%$ and above and can last as long as 100,000 hours of continuous operation - but they cost more, and thus, it takes years to recover the cost of the bulb. The illumination from
LEDs is also more directional than that from filament bulbs, so LEDs is also more directional than that from filament bulbs, so
further developments might be needed to obtain a quality of light urther developments might be needed to obtain a quality of light
acceptable to the consumer. The article by Humphreys in this issue discusses in detail the materials issues that must be resolved to enable the generation of white light with acceptable charac-

As described by Gielen, Newman, and Patel in their article in this issue, industry accounts for one-third of the primary energy supply and provides opportunities for innovation not
only to improve efficiency but also to reduce carbon emissions. Achieving increased efficiency and reduced emissions in industry feeds back to the very start of the energy cycle: industry refines the energy sources and makes the materials that supply new (and old) technologies. The iron and steel industry consumes over $1 \%$ of the total industrial energy supply. Many energy efficiency in iron making by substituting blast furnaces with reactors that would not require the coking of coal or iron ore agglomerates or sinters. A recent innovation, Finex ${ }^{\oplus}$ developed by a South Korean Corporation, Posco-for cokstance, operates win ordinary coal and iron ore fines. Even energy efficient by utilizing coke oven gases for hydrogen recovery, methanol synthesis, and electric power generation. Coke oven gases could also possibly be used for direct reduction of iron ores.

Cement manufacturing competes with iron and steel in
annual $\mathrm{CO}_{2}$ emissions, at around 1.7 trillion $\mathrm{kg}$ per rear $\mathrm{Alarg}$ fraction of the emissions around 1.7 trillion $\mathrm{kg}$ per year. A large from the process itself, specifically the making of clinkers at high temperatures. When the process is not optimized, $\mathrm{CO}_{2}$ emissions can be as high as $1 \mathrm{~kg}$ of $\mathrm{CO}_{2}$ for every kilogram of ement produced. Many attempts have been made to minimize energy consumption and reduce $\mathrm{CO}_{2}$ emissions by opting for coal-fired power stations instead of clinkers.

If these innovations enhance performance and are energyefficient, why are they not widely adopted as they are developed? The dissemination of innovations is a complex process. into the market These are the disruptive tocho pesthation vide goods and services in new ways in areas where none existed or where those that did exist were not profitable. Most innovations, however, are incremental and tend to be costly in the beginning. They are perceived as being for the public good rather than for private profitability. For instance, minimizing not be seen by firms as necessary for a company's profitability According to Paul David, a professor of economics at Stanford University, even electricity took more than 100 years to become commonplace in the U.S. industrial infrastructure. ${ }^{48}$

Part of the reluctance to implement new technologies might relate to the associated efforts required to create new supply tures. With an industry as immense as energy, even small changes involve large risks. New processes, to start with, are not economical and might also not realize their full potential. Unless there are market externalities, barriers associated with ties can be in the for of tax incentives or the inpe thiolities can be in the form of tax incentives or the imposition of
taxes that make the old processes less competitive and give newer technologies a boost toward the benefits of mass pro-
duction. Both Germany and Japan are providing incentives to sustainable energy generators whereby electricity grids are mandated to buy power from such providers at costs that are attractive to the producers of power. In Bangalore, India, new
home builders are mandated to install solar water heaters in preference to heaters powered by electricity. Externalities ca
also take into account costs to society that are not explicitly paid during production. Carbon pricing for instance, can make newer innovations competitive if they have reduced carbo dioxide emissions. Will such incentives make solar energy competitive? Solar energy proponents maintain that there has not been a sufficient increase in the scale of production nor has there been clearly defined market support from many govern-
ments that could have brought the cost of the resource down. Likewise, what factors might make LEDs commonplace for general lighting? Both the market support and new technologies that can bring down the learning curve dramatically Ture 8) are part of this process.

作 can enhance performance an know which technologies will be the winners and which the losers. But understanding the energy landscape can guide the development of well-chosen experiments - in the laboratory structure far into this century.

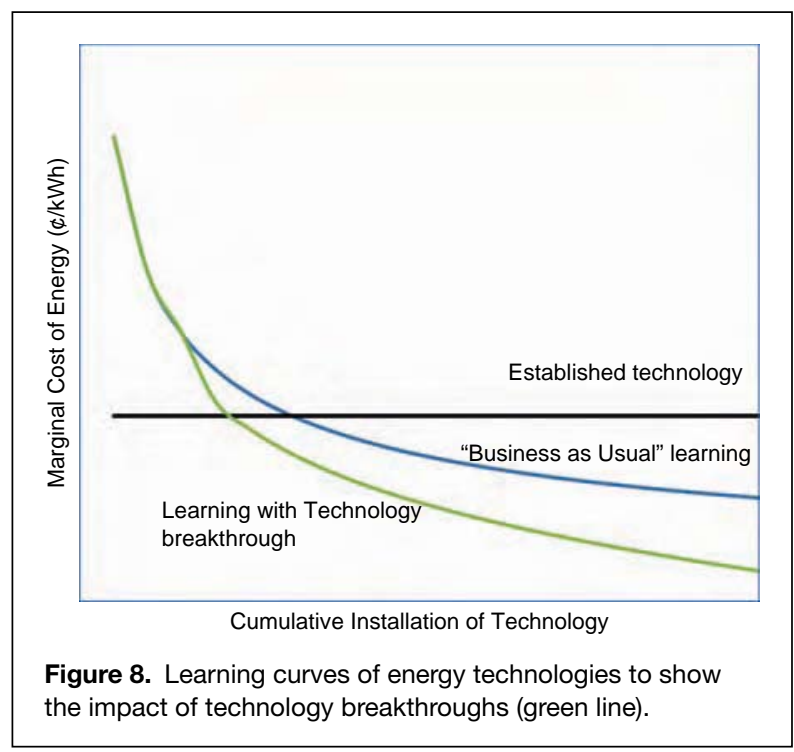

A Concluding Note

The Industrial Revolution of the 18th and 19th centuries was enabled by the discovery of energy resources and the making of materials to harness that energy. Over many years, the list of the materials and properties that we seek has grown: from coal and
iron to uranium, silicon, nickel-based superalloys, and so on. The to unim, silicon, nickel-based superalloys, and so onnamic, electrical, electronic, catalytic, and mechanical propeties of materials. But the vision of enriching human society with 40 terawatts of power in 30 years calls also for our understanding of materials properties that were hitherto unexplored an tailoring those properties for the performance we require. Thi als for catalysts and hydrogen storage, and materials that effciently and economically convert solar energy into usable forms. The sheer scale of the scientific challenges in the energy sector is overwhelming. The driver for the coming decades is not just the harnessing of new energy sources, but also the development of energy technologies from source to use with optimized efficiency and no or minimal $\mathrm{CO}_{2}$ emissions. There
should also be an improved understanding of the behavior of materials and structures that can sequester $\mathrm{CO}_{2}$ or convert it more decades. How materials scientists and engineers respond to these challenges will determine how successful our society is going to be in generating sustainable and pollution-free in the coming decades.

Acknowledgments

This collection of articles is the result of intense work by a by the MRS Bulletin Energy Project Organizing globe led (VSA, George W. Crabtree, ELF, David S. Ginley, Colin J. Humphreys, Keiichi N. Ishihara, Kathleen C. Taylor, and Rahul Tongia), the MRS Bulletin Editorial Board (Paul S. Drzaic, for this issue, see elsewhere in the issue.

For this introductory article, the authors also thank $\mathrm{N}$. Balasubramanian for discussions during the preparation of this manuscript and especially Anshu Bharadwaj for his critical comments and for sharing his data. John Ziagos, Jane C.S. Long, helped in the development of the energy flow diagram for India. ELF thanks the Department of Materials Engineering of the
Indian Institute of Science for their hospitality. VSA thanks the

The full MRS Bulletin issue, "'Harnessing Materials for Energy,",
includitits was funded in part by the Department of Energy. Office of Basic Energy Sciences, under Award Number DE-FG02-07ER46436 (John Vetrano and Harriet Kung). Additional support was provided by First Solar, Inc.; General Motors Corporation; HelioVolt Corporation; Applied Materials, Inc.; Agilent Technologies; and the
Center for Study of Science, Technology and Policy (CSTEP). Fo full funding details, see the sponsor page in this issue and www mors. org/bulletin energy. The views and opinions of authors expressed government or any agency thereof.

References 2. Energy Information Administration, U.S. Department of Energy,
2international Energy Annual, 2005 (EIA, US. Department of Energy Washington, DC, 2005.

3. United Nations Development Programme, Human Development Report,
Fighting Climate Change: Human Solidarity in a Divided World (UNDP. 4. J. Holdren, presented at the American Association for the Advancement of
Science 2007 Robert C. Barnard Environmental Lecture, Washington, DC, 18 Science 2007
October 2007.

5. G. Sachs, Glob. Econ. Wkly. 04/36 (2004)

6. V. Vaitheeswaran, I. Carson, Z000: The Global Race to Fuel the Car of the Future (Twelve Publishing, OCtober 1 12007). Report (AR4) (IPCC, 2007).
8. Danish Energy Authority, Danish Annual Energy Statistics (DEA, 8. Danish Energy Authority, Danish Annall Energy Stalsilics (DEA,
Copenhagen, Denmark, 2006). Copenhagen, Denmark, 2006).
9. Ea Energy Analyses, “50\% Wind Power in Denmark in 2025 ” (Ea Energy
Analyses, Kobenhavn, Denmark, 2007; wwww.eaea.dk) (accessed January 2008).
10. Such charts may be accessed at https:///ed.lllnl.gov/flow/ and are a
product of Lawrence Livermore National Laboratory, Livermore, CA 94550.
US S Flow diagram (2008) U.S.FFow diagram (2008) LLNL-PRES-401626 data is based on DDEEEIA-
0384 (2006), June 2007. If this information or a reproduction of it is used, credit must be given to the Lawrence Livermore National Laboratory and the
11. Massachusetts Institute of Technology, The Future of Coal: Options for 12. E.S. Rubin, C. Chen, A.B. Rao, Energy Policy 35 (9) (2007). 13. J. Friedmann, "Fire in a Hole: Underground Coal Gasification" (Science CA, April 2007; wwww.IInl.gov/str//Aprilo7//Friedmann.htmI) (accessed January 2008).
14. M.K. Hubbert, presented at the Spring Meeting of the Southern District,
Division of Petroleum, American Petroleum Institute, San Antonio, Texas 15. K.S. Deffeyes, Beyond Oil: The View from Hubbert's Peak (Hill and Wang,

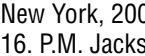
16. P.M. Jackson, Why the Peak Oil Theory Falls Down: Myths, Legends, and
the Future of Oil Resources (Cambridge Energy Research Associates, Cambridge, MA, 2006).

17. Beyond Petroleum, "Statistical Review of World Energy 2007" (BP, 2007;
www.bp.com/productlanding.do?categoryld $6848 \&$ \&contentld=7033471) (accessed January 2008).
18. Energy Information Administration, U.S. Department of Energy, "World Washington, DC, 2006).

19. National Energy Board, "Canada's Oil Sands: Opportunities and Challeng

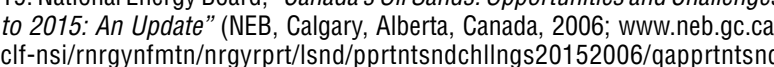
chlllngs20152006-eng.hthll) (accessed January 2008 .

20. H. Shapouri, J.A. Duffield, W, Wang, "The Energy Balance of Corn Ethano: An Update" (Agricultural Economic Report No. 814, Office of the Chief
Economist, Office of Energy Policy and New Uses, U.S. Department 21. A. Farrell P. P. Pevin D, B. 2002).

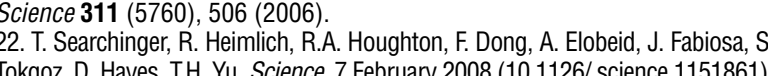

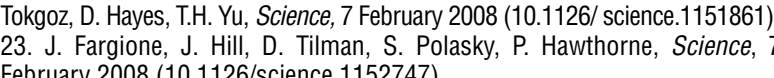
February 2008 (10.1126/science.1152747). 24. A. Bharadwaj, R. Tongia, V.S. Arunachalam, Cur.
25. IOGEN Corporation, Ottawa, Ontaric, Canada.
26. Celunol Corporation. Dedham. MA USA.

26. Celunol Iorporataion, Dedham, MA, UAA.
27. A. Bharadwai, R. Tongia, V.S. Arunachalam, Curr. Sci. 92 (9) (2007)

27. A. Bharadwaj, R. Tongia, V.S. Arunachalam, Curr. SCi. 92 (9) (2007),
28. Energy Information Administration, U.S. Department of Energy, 'World
Net Nuclear Electric Power Generation, 1980-2005. (ElA, U.S. Department of 29. Massachusetts Institute of Technology, The Future of Nuclear Power (MiT, Cambridge, MA, 2003; ISBN 0-615-12420-8).
30. International Atomic Energy Agency, “Annual Report for 2006" (IAEA, Vienna, Austria, 2006).

32. International Atomic Energy Agency, "Nuclear Power for Greenhouse Gas Mitigation" (IAEA, Vienna, Austria, November 2000).
33. U.S. Department of Energy, office of Science, "Basic Research Needs for 33. U.S. Department of Energy, Office of Science, "Basic Research Needs for
Solar Energy Utilization, Report on the Basic Energy Sciences Workshop on Solar Energy Utilization" (U.S. Department of Energy, Washington, DC, 2005;

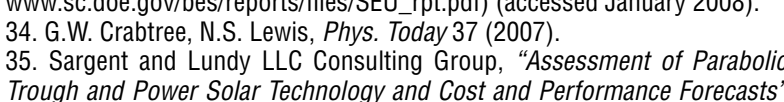
(Sargent and Lundy, Chicago, IL, USA, 2003).

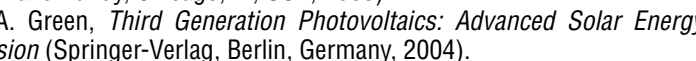
37. T. Surek, J. Cryst. Growth 275,292 (2005).
. 2004$)$.

38. Energy Efficiency and Renewable Energy, U.S. Department of Energy,
"Solar Energy Technologies Program: Solar America Initiative" (EERE, U.S. Department of Energy, Washington, DC, 2007).
39. A. Bharadwai, "Working Report: Energy Balance of Various Renewable 39. A. Bharadwaj, "Working Report: Energy Balance of Various Renewable
Sourcese" Conter for Study of coience, Technology and Policy, Bangalore,

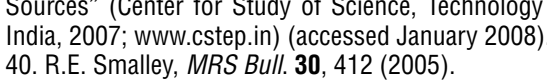

40. R.E. Smalley, MRS Bull. 30, 412 (2005).
41. World Wind Energy Association, "New World Record in Wind Power
Capacty: 14 G

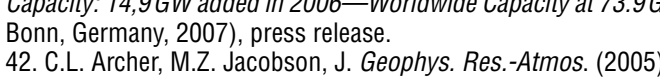
42. C.L. Archer, M.Z. Jacobson, J. Geoophys. Res.-Atmos. (2005).
43. Natitional Energy Technology Laboratory, U. U. Department of Energy, "Fuel
Celll Handbook" (NETL, U.S. Department of Energy, Office of Fossil Energy, Morgantown, WW, 2004) 44. U.S. Department of Energy, "National Hydrogen Energy Roadmap" (based
on the results of the National Hydrogen Energy Roadmap Workshop. 
45. Committee on Alternatives and Strategies for Future Hydrogen Production and Use, National Research Council, National Research Council and National Academy of Engineering, "The Hydrogen Economy: Opportunities, Costs, Barriers, and R\&D Needs" (National Academies Press, Washington, DC, 2004).

46. Integrated Environmental Control Model, Carbon Sequestration Edition, Carnegie Mellon University, Pittsburgh, PA, USA.

47. A.I. Taub, P.E. Krajewski, A.A. Luo, J.N. Owens, JOM 59 (2), 48 (2007). 48. P.A. David, Am. Econ. Rev. 80 (2), 355 (1990).

49. Energy Information Administration, U.S. Department of Energy, "International Energy Annual 2004" (EIA, U.S. Department of Energy, Washington, DC, 2006).

50. A. Bharadwaj, J.P. Ziagos, R. Lehman, R. Tongia, V.S. Arunachalam, Working Report: Energy Flow Diagram for India and Its Implications for
Climate Policy (Center for Study of Science, Technology and Policy, Bangalore, India, 2008).

51. Energy Information Administration, U.S. Department of Energy, 2007. 52. Organization of Petroleum Exporting Countries, "Annual Statistical Bulletin" (OPEC, Vienna, Austria, 2006).

53. P.J. Meier, P.P.H. Wilson, G.L. Kulcinski, P.L. Denholm, Energy Policy 33, 1099 (2005).

54. P.J. Meier, "Life Cycle Assessment of Electricity Generation Systems and Applications for Climate Change Policy Analysis" (University of Wisconsin, Madison, WI, 2002).

55. S.W. White, G.L. Kulcinski, Fusion Eng. Des. 48 (248), 473 (2000).

56. J.B. Heywood, Internal Combustion Engine Fundamentals. (McGraw-Hill, New York, 1988).

57. L.V. Krishnan, Chennai, India, personal communication, 2007.

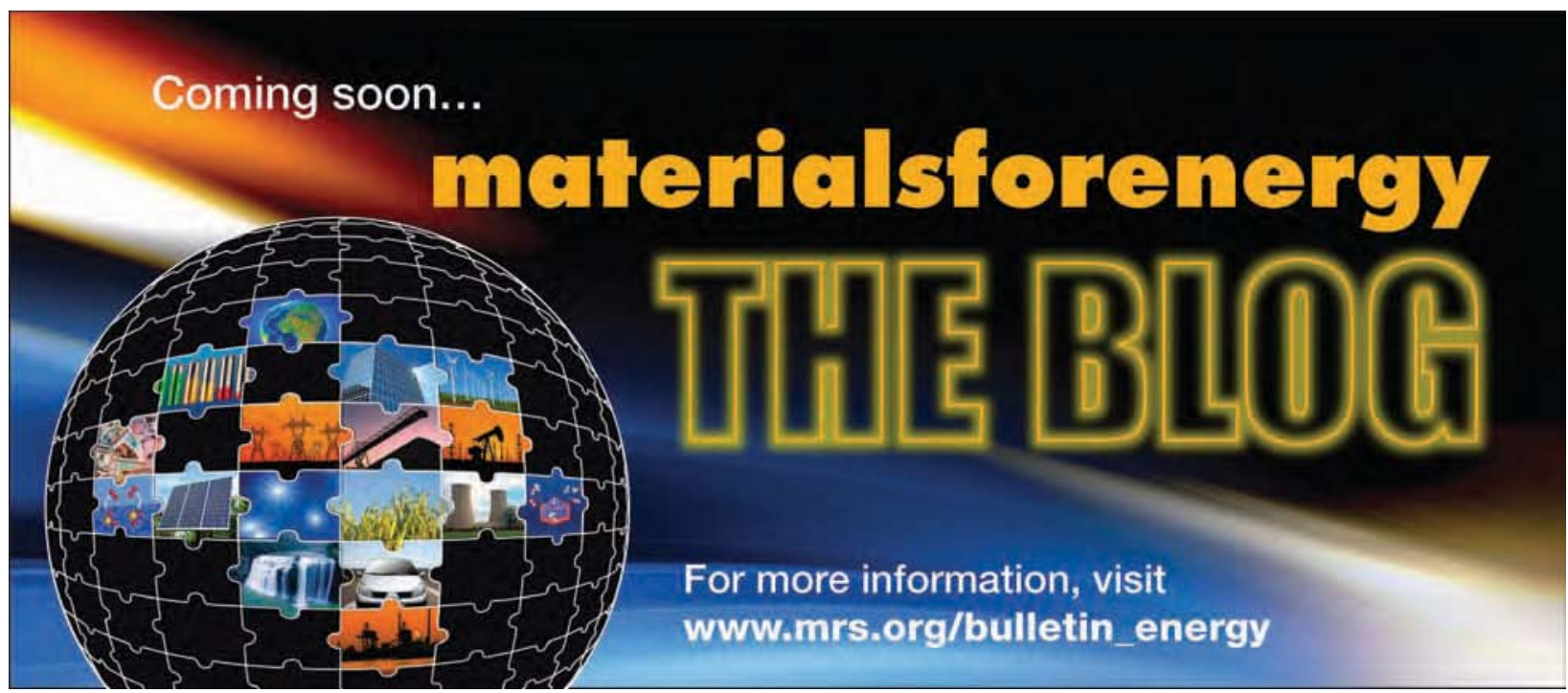

\section{Materials Characterization}

Vibrating Sample

Magnetometer Systems

Fields to $3.1 \mathrm{~T}$

Temperature options

from $4.2 \mathrm{~K}$ to $1273 \mathrm{~K}$

in Vector, autorotation, and MR options

E Quick disconnect sample rods for fast and reproducible sample exchange

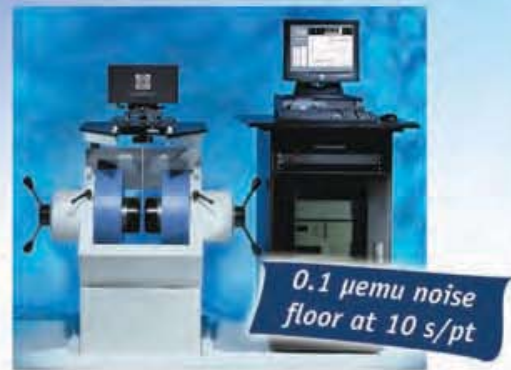

Hall Effect

Measurement Systems

- Fields to $9 \mathrm{~T}$

E Measure up to 6 -inch wafers or up to 4 samples at a time

- $\mathrm{AC}$ current and variable temperature options

- $\mathrm{QMSA}^{\circ}$ software resolves individual carrier mobilities and densities of multi-carrier devices

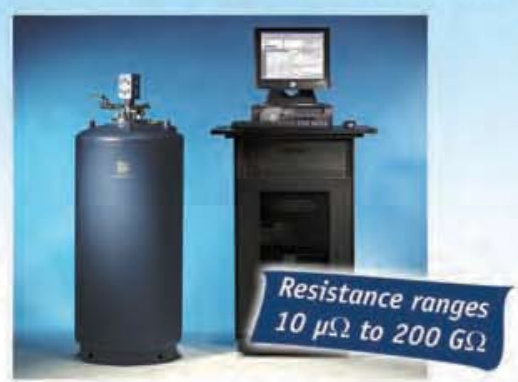

\section{Probe Stations}

Frequencies from DC to $67 \mathrm{GHz}$

- Temperatures from $1.5 \mathrm{~K}$ to $475 \mathrm{~K}$

Up to 6 micromanipulated probe arms

- Up to 4-inch wafer probe capability

a Magnet fields, load-lock, high vacuum, CCR

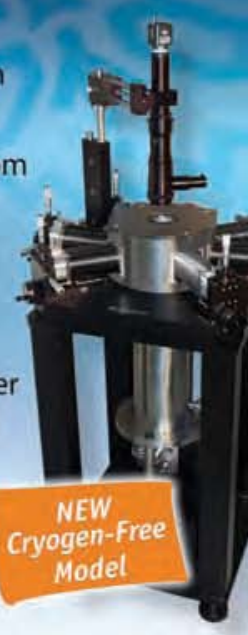

\section{LakeShore.}

e-mail: info@lakeshore.com www.lakeshore.com 


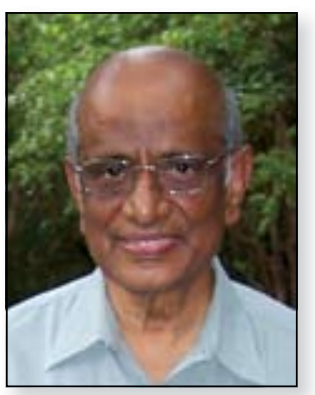

V.S. Arunachalam

V.S. Arunachalam, chair of the organizing

committee for this issue of MRS Bulletin, can be reached at 547, 9th Cross, JP Nagar III Phase,

Bangalore 560078, India; tel. +91-80-2649-1399,

and e-mail vsa@cmu.edu.

Arunachalam is chair of the Center for Study of Science, Technology, and Policy (CSTEP), a Bangalore-based nonprofit research corporation that studies technology and policy issues. He was the scientific advisor to the Defense Minister of India for more than a decade and head of India's largest research and development institution-Defence Research and

Development Organization (DRD0). Arunachalam

initiated and headed India's major defense projects, including light combat aircraft and integrated guided missiles programs. He also advised the government on large and innovative human development and infrastructure building programs. He continues to hold a distinguished service professorship at Carnegie Mellon University and is an honorary professor of engineering at the University of Warwick in the United Kingdom.

Arunachalam is a recipient of numerous honors and awards including Padma Vibhushan, the highest civilian award for that year from the president of India. He was the past president and fellow of the Indian National Academy of Engineering, Indian Institute of Metals, and a fellow of

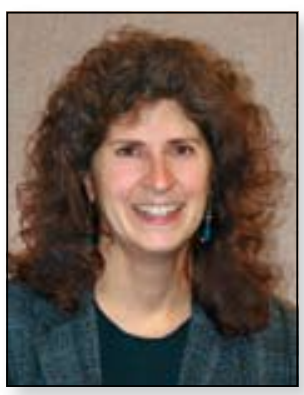

Elizabeth L. Fleischer

the Indian National Science Academy and Indian Academy of Sciences. Arunachalam also is a fellow of the Royal Academy of Engineering (UK).

\section{Elizabeth L. Fleischer,}

project leader for the organizing committee in this issue of MRS Bulletin, can be reached at the Materials Research

Society, 506 Keystone Dr. Warrendale, PA 150867573, USA; tel. 724-7793004, ext. 521, fax

724-779-8313, and e-mail fleischer@mrs.org.

Fleischer has been employed by the Materials Research Society (MRS) since 1991 as technical editor and then editor of MRS Bulletin. She received her BSE degree in 1985 from the University of Pennsylvania, her MS degree in 1988 from Cornell University, and her $\mathrm{PhD}$ degree in 1991 from Cornell-all in materials science and engineering. Fleischer was a research associate at the Tandem Accelerator Laboratory at the University of

Pennsylvania in 1983 and a technical associate in the III-V Semiconductor Processing Group at AT\&T Bell Laboratories in 1984. Fleischer is a member of the publications commission of the International Union of Materials Research Societies; was a principal investigator for MRS's traveling science exhibit, Strange Matter; and served as an advisor to Cornell University's 2004 "Too Small To See" science exhibition. From 2003 to 2004, she was a

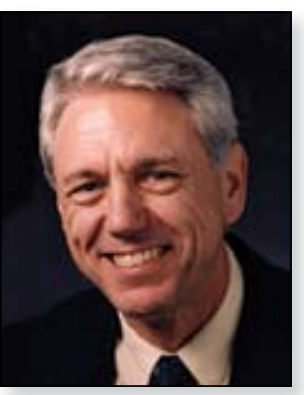

George W. Crabtree

part of the Institute for Community Leadership in Education. Fleischer was an AAAS Mass Media Science and Engineering fellow in 1989, and is a scientific member of the Böhmische Physical Society, and is a column editor for the Council of Science Editors'

Publication Science Editor. Fleischer also is a member of the American

Association for the

Advancement of Science, American Chemical

Society, American Physical Society, Materials Research Society, and Council of Science Editors.

George W. Crabtree,

organizing committee member for this issue of

MRS Bulletin, can be reached at Materials Science Division, Argonne National Laboratory, 9700 S. Cass Ave, Argonne, IL 60439, USA; tel. 630252-5509, fax 630-252-

8042, and e-mail crabtree@anl.gov.

Crabtree is a senior scientist at Argonne National Laboratory. He received his $\mathrm{BS}$ degree from Northwestern University, Evanston, $\mathrm{IL}$, in science engineering; his MS degree from University of Washington, Seattle, in physics; and his PhD degree from University of Illinois at Chicago in solid state physics. At Argonne, Crabtree has worked on the electronic behavior of transition metal, organic, heavy fermion, and hightemperature superconducting compounds, and on materials for energy conversion.

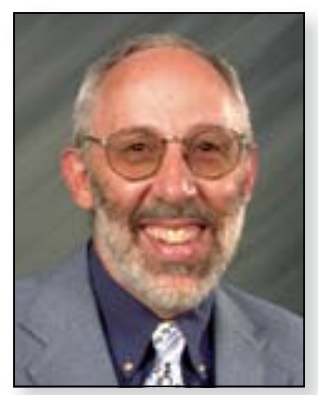

David S. Ginley

David S. Ginley, organizing committee member for this issue of MRS Bulletin, can be reached at National Renewable Energy Lab, MS 3211, SERF W102, 15313 Denver W. Pkwy. Golden, C0 80401, USA tel. 303-384-6573, fax 303-384-6430, and e-mail dave_ginley@nrel.gov.

Ginley is the group manager in Process Technology and Advanced Concepts at the National Renewable Energy Laboratory (NREL). He received his $\mathrm{BS}$ degree in mineral engineering chemistry from Colorado School of Mines in 1972, and his $\mathrm{PhD}$ degree in inorganic chemistry from Massachusetts Institute of Technology in 1976. He is an adjunct professor of physics at University of Colorado at Boulder, and an adjunct professor of materials science/physics at the Colorado School of Mines (CSM). Ginley's research interests include basic science and application of transparent conducting oxides, ferroelectric materials, organic materials and nanomaterials, and the development of nextgeneration process technology for materials and device development including combinatorial methods, direct write materials, composite materials and non-vacuum processing. PV related projects include direct write optoelectronic materials and contacts, organic photovoltaics (OPV), nanomaterials for $\mathrm{PV}$, new TCOs for PV, thin-film template layers for highquality PV thin films, and high throughput

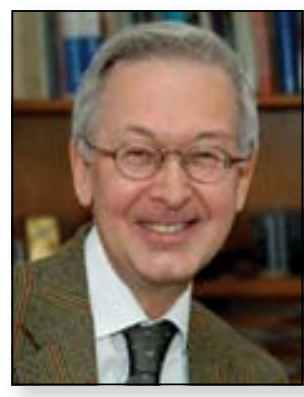

Colin J. Humphreys

methodologies for PV materials and device development. He has over 300 papers and 25 patents. He is a fellow of the ECS on the board of directors of the MRS and is an associate editor of the Journal of Materials Research.

Colin J. Humphreys, organizing committee member for this issue of MRS Bulletin, can be reached at the Department of Materials Science and Metallurgy, University of Cambridge, Pembroke Street, Cambridge, CB2 3QZ, UK; tel. +44-1223334457, fax +44-1223334437, and e-mail colin humphreys@msm.cam. ac.uk

Humphreys is the Goldsmiths' Professor of Materials Science at Cambridge University in the United Kingdom. He graduated with a degree in physics from Imperial College, London, and earned his $\mathrm{PhD}$ degree from the Cavendish Laboratory Cambridge. Before joining Cambridge in 1990, Humphreys was a lecturer in the Materials Department at the University of Oxford, and then head of materials engineering at the University of Liverpool. In addition to his position at Cambridge, Humphreys is a professor of experimental physics at the Royal Institution in London and a fellow of Selwyn College, 


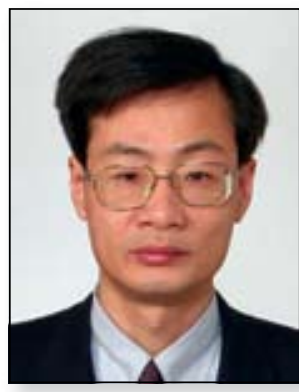

Keiichi N. Ishihara

Gallium Nitride Centre. Humphreys' research interests include all aspects of electron microscopy and analysis, semiconductors (particularly gallium nitride), ultra-hightemperature aerospace materials, and superconductors. Humphreys' hobby is reconstructing what happened in ancient historical events using modern-day science. He was president of the Institute of Materials, Minerals, and Mining in 2002 and 2003. He then served as the chair of its managing board.

Humphreys is a fellow of the Royal Academy of Engineering; a member of the Academia Europaea; a liveryman of the Goldsmiths' Company; a member of the Court of the Armourers and Brasiers' Company; a Freeman of the City of London; a member of the John Templeton

Foundation in the USA and the honorary president of the Canadian College for Chinese Studies in Victoria, Canada. In addition, Humphreys was president of the physics section of the British Association for the Advancement of Science from 1998 to 1999, and a fellow with the Public Understanding of Physics, Institute of Physics, from 1997 to 1999. He has received medals from the Institute of Materials, the Institute of Physics, and the Royal Society of Arts; and given various memorial lectures throughout the world. In 2001, Humphreys received an honorary DSc degree from the University

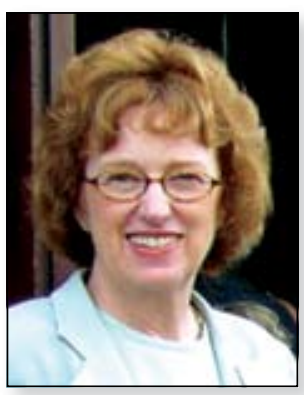

Kathleen C. Taylor

of Leicester. Other awards include the European Materials Gold Medal, the Robert Franklin Mehl Gold Medal from The Materials, Minerals, and Metals Society in 2003, and the CBE in the New Year's Honours for 2003. In addition, Humphreys is the author of The Miracles of Exodus: A Scientist Reveals the Extraordinary Natural Causes Underlying the Biblical Miracles.

Keiichi N. Ishihara, organizing committee member for this issue of MRS Bulletin, can be reached at the Department of Socio-environmental Energy Science, Graduate School of Energy Science, Kyoto University, 6068501 Yoshida, Sakyo-ku, Kyoto, Japan; tel. +81-75753-5464, and e-mail ishihara@energy.kyotou.ac.jp.

Ishihara is a professor in the Department of Socio-environment of Energy Science, Graduate School of Energy Science, at Kyoto University in Japan. He received his $\mathrm{BS}, \mathrm{MS}$, and $\mathrm{PhD}$ degrees from the Department of Metal Science at Kyoto University in 1981, 1983, and 1986 , respectively. Ishihara has worked at Kyoto University since 1986. In addition, he is a member of the Technical Committee of New Energy and Industrial Technology Development Organization, Japan.

Kathleen C. Taylor, organizing committee member for this issue of MRS Bulletin, can be

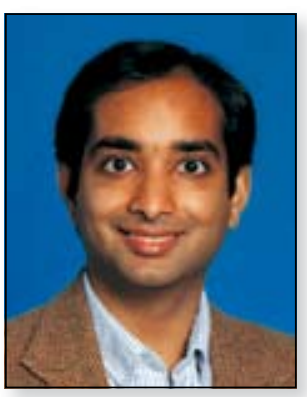

Rahul Tongia

reached by e-mail at kctylr@aol.com.

Taylor is the retired director of the Materials and Processes Laboratory of General Motors

Corporation. She received her $A B$ degree from Douglass College and her $\mathrm{PhD}$ degree in physical chemistry from Northwestern University. Currently, Taylor serves on the board of directors of the National Inventors Hall of Fame, the US Department of Energy's (DOE) Hydrogen and Fuel Cell Technical Advisory Committee (HTAC), and the DOE's Basic Energy

Sciences Advisory Committee. She has been president of the Materials Research Society and chair of the board of directors of the Gordon Research Conferences. Taylor also serves on the National Research Council's committee for a review of the FreedomCAR and Fue Research Program. Also, she was elected to the National Academy of Engineering in 1995, is a fellow of SAE

International, and is a foreign member of the Indian National Academy of Engineering. Taylor's honors include the Garvan Medal from the American Chemical Society.

Rahul Tongia, organizing committee member of this issue of MRS Bulletin, can be reached at the

Department of Engineering and Public Policy, Carnegie Mellon University, Baker Hall 129, Pittsburgh, PA 5213, USA e-mail tongia@cmu.edu,

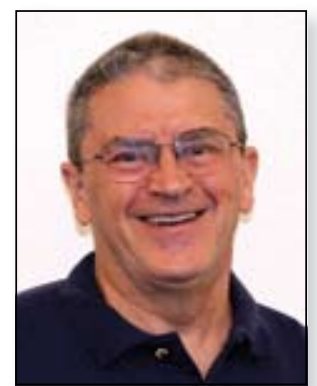

Michael C. Driver

and www.cs.cmu. edu/ rtongia.

Tongia is a faculty member in the Departments of Engineering and Public Policy, and the Program in Computation,

Organizations, and Society in the School of Computer Science at Carnegie Mellon University in Pittsburgh,

PA. Tongia received his ScB degree in electrical engineering from Brown University, and his $\mathrm{PhD}$ degree in engineering and public policy from Carnegie Mellon. He has extensive experience working with, and advising, a number of multilateral organizations such as the United Nations and World Bank, as well as Electric Utilities in the USA and India. Tongia's work is interdisciplinary, spanning infrastructure technology and policy, with a focus on developing regions. In addition, he is a senior fellow at the Center for Study of Science, Technology, and Policy (CSTEP), in Bangalore, India.

Michael C. Driver, Coproject leader for the organizing committee in this issue of MRS Bulletin, can be reached at Materials Research Society, 506 Keystone Dr., Warrendale, PA 15086-7573, USA; tel. 724-779-3004, ext. 401, and e-mail driver@mrs.org.

Driver is the director of information services (publishing) at the Materials Research Society, where his main responsibilities are with MRS Bulletin, the Journal of Materials Research, and MRS Symposium

Proceedings. Driver received his BSc degree in

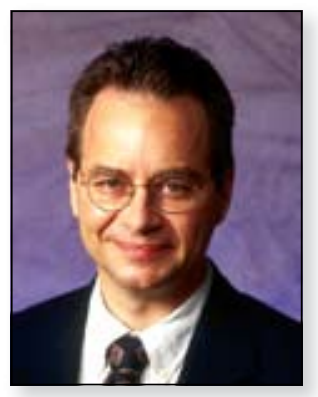

Paul Drzaic

physics, with honors, and his $\mathrm{PhD}$ degree in electronic and electrical engineering - both at the University of Birmingham, England. When he worked in industry, Driver's research interests included semiconductor devices, particularly gallium arsenide and silicon nitride transistors, cadmium-zinc-telluride gamma ray detectors, and monolithic integrated circuits for power at microwave frequencies. Also, Driver is a life fellow of the Institute of

Electronic and Electrical Engineers (IEEE).

Paul Drzaic, chair of MRS Bulletin editorial board, can be reached at Unidym Inc., 1430

O'Brien Ave., Suite G, Menlo Park, CA 94025, USA; tel. 650-462-1935, fax 650-462-1939, and email pdrzaic@unidym.com Drzaic is Chief

Technology Officer at Unidym Inc. in Menlo

Park, California,

developing electronic materials and devices using carbon nanotube technologies. Drzaic joined Unidym after serving as vice president for advanced development at Alien Technology Corporation, helping develop novel, flexible RFID devices. Prior to Alien, Drzaic, was the first director of technology at E Ink corporation, leading the team of engineers and scientists that produced the first active matrix electronic paper prototypes, for which he 


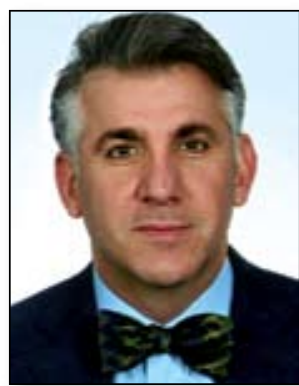

Massoud Amin

has 52 patents, 20 journal publications, and a monograph on liquid crystals. He is presidentelect of the Society for Information Display (SID), is a Fellow of the SID, and has held several leadership positions within the Materials Research Society. He earned a BS degree in chemistry from the University of Notre Dame and a PhD degree in chemistry from Stanford University.

Massoud Amin can be reached at University of Minnesota, $1300 \mathrm{~S}$. Second St., \#510, Minneapolis, MN 55454, USA; tel. 612-624-5747, fax 612-624-7510, e-mail amin@umn.edu, and http://umn.edu/ amin.

Amin is a professor of electrical and computer engineering, directs the Center for the Development of Technological Leadership, and holds the Honeywell/ H.W. Sweatt Chair in Technological Leadership at the University of Minnesota. Before joining the University of

Minnesota in March 2003, Amin was with the Electric Power Research Institute (EPRI), where he initiated and developed the smart self-healing grid, and led the development of more than 24 technologies transferred to industry. After September 11, 2001, he directed all securityrelated research and development, and twice received Chauncey Awards at EPRI, the institute's highest honor. Amin is a member of the Board on Infrastructure

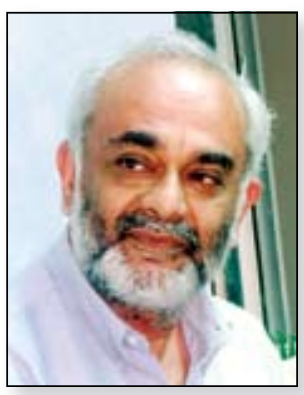

Dipankar Banerjee

and the Constructed Environment at the U.S National Academy of Engineering, a member of the Board on Mathematical Sciences and Applications at the National Academy of Sciences, and a senior member of IEEE.

Dipankar Banerjee can be reached at the Defence

Research and

Development Organisation, 310, DRD0 Bhavan, Rajaji Marg, New Delhi 110011, India; tel. +91-11-

23016640, fax +91-1123016706, and e-mail dbanerjee@hqr.drdo.in.

Banerjee is chief controller of research and development at the Defence Research and Development Organization (DRDO), India, and coordinates its aeronautics and materials programs. He graduated from the Indian Institute of Technology, Madras, in metallurgy, and obtained his $\mathrm{PhD}$ degree from the Indian Institute of Science, Bangalore. Banerjee started his career at the Defence Metallurgical Research Laboratory at Hyderabad in 1979, and was the director of the laboratory from 1996 to 2003. Banerjee is known for his contributions to the science, technology, and application of titanium alloys. He received India's national award-Padma Shri-in 2005, and is a fellow of the Indian Academy of Sciences and the Indian National Academy of Engineering.

Sally M. Benson can be reached at Stanford

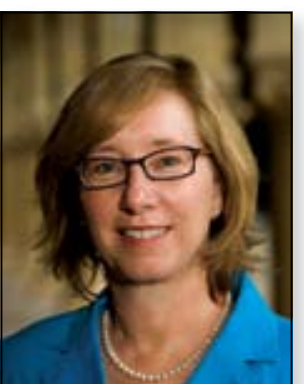

Sally M. Benson

University, Global Climate and Energy Project, 4230 Jerry Yang and Akiko Yamazaki Environment and Energy Bldg., 473 Via Ortega, Stanford, CA 94305, USA; tel. 650-7250358, and e-mail smbenson@stanford.edu.

Benson is a research professor in the Energy Resources Engineering Department in the School of Earth Sciences at Stanford University, and the executive director of the Global Climate and Energy Project. She received her MS and $\mathrm{PhD}$ degrees from the University of California in materials science and mineral engineering. Benson joined Stanford in 2007 after working at Lawrence Berkeley National Laboratory in a number of capacities, including Earth Science Division Director, Associate Laboratory Director for Energy Sciences, and Deputy Director for Operations.

Peter Bonfield can be reached at Building Research Establishment, Bucknalls Lane, Watford WD25 9XX, UK; tel. +441923-664200, fax +44-

1923-664785, and e-mail bonfieldp@bre.co.uk.

Bonfield is the chief executive of Building Research Establishment (BRE). A materials engineer with a $\mathrm{PhD}$ degree in fatigue of wood composites, his fifteen-year career in construction has focused on driving innovation and improved sustainability across all construction sectors. Most recently, Bonfield established a fiveyear contract with Marks

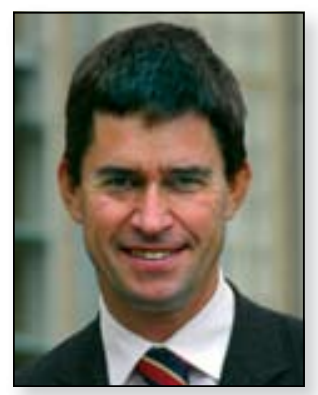

Peter Bonfield

and Spencer to help with delivery of its $£ 200$ million eco-plan. Bonfield is currently on part-time secondment to the Olympic Delivery Authority, where he has helped create the sustainable development strategy for the Olympics. In addition, Bonfield is a former international road racing cyclist and Ironman triathlete. He has acted as bike coach for two UK competitors in the women's triathlon in the Athens Olympics.

Harald Böttner can be reached at Fraunhofer Institute for Physical Measurement Techniques, Heidenhofstraße 8, D79110 Freiburg, Germany; tel. +49-761-8857-121, and e-mail harald.

boettner@ipm.fraunhofer. de.

Böttner is head of the Department Thermoelectric Systems at the Fraunhofer Institute for Physical

Measurement Techniques in Freiburg, Germany. He graduated in chemistry from the University of Münster (UM), Germany, and also received his $\mathrm{PhD}$ degree from UM in 1977. In 1978, Böttner joined the Fraunhofer ISC, Würzburg. He moved to his current position in 1980. Böttner developed IV-VI infrared semiconductor lasers through 1995. From 1995 to 2003 , he worked with semiconductor gas sensors. He started working with activities in thermoelectrics in 1989.

Böttner's research activities are focused on thin film and nanoscale thermoelectrics, as well as microelectronics-related device technology. He has

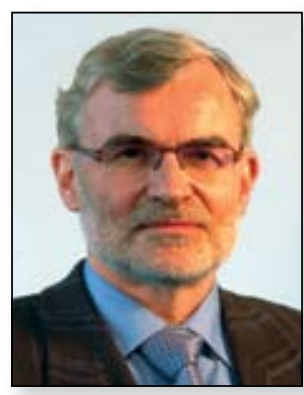

Harald Böttner

authored or co-authored approximately 20 patents and more than 100 papers in journals, proceedings, reviews, and chapters in handbooks. Böttner also

is a board member of the International

Thermoelectric Society.

Povl Brondsted can be reached at Materials Research Department, Risø-DTU, National Laboratory for Sustainable Energy, The Technical University of Denmark, AFM-228, PO Box 49,

Fredriksborgvej 399, DK4000 Roskilde, Denmark; tel. +45-46-77-57-04, fax $+45-46-77-57-58$, and e-mail povl.brondsted@ risoe.dk.

Brøndsted has been head of the research program on composites and material mechanics at Risø-DTU since 2000. He earned his $\mathrm{PhD}$ degree from the Technical University of Denmark (DTU) in 1977. During his PhD degree study and after graduation,

Brøndsted was employed in the Material Research Department at Risø National Laboratory (RNL). His research at RNL included mechanical behavior, fatigue, and fracture mechanics of metals and composite materials. Brøndsted joined the first teams to qualify and design wind power turbines in 1976.

Joseph A. Carpenter, Jr. can be reached at the Office of FreedomCAR and Vehicle Technologies, EE2G Rm. 5G-030, US

Department of Energy, 1000 Independence Ave. 


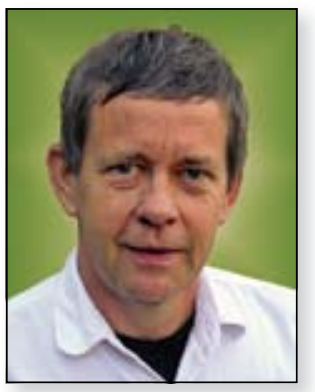

Povl Brøndsted

SW, Washington, DC 20585, USA; tel. 202586-1022, and e-mail joseph.carpenter@ee.doe. gov.

Carpenter is currently the technology development manager for the U.S. Department of Energy (DOE) Lightweighting Materials effort, part of the FreedomCAR and Hydrogen Fuels Initiative between DOE and the U.S. automotive and energysupply industries. He holds bachelor and doctoral degrees in materials from Virginia Tech. Carpenter also has held research and research management positions at Chrysler Corporation, the Oak Ridge National Laboratory, and the National Institute for Standards and Technology, before joining the U.S. DOE. He lives with his wife on a floating home in the Potomac River in Washington, DC.

Lidong Chen can be reached at Shanghai Institute of Ceramics, Chinese Academy of Sciences, 1295 Dingxi Rd., Shanghai 200050 China; tel. +86-21-52414804, and e-mail cld@ mail.sic.ac.cn.

Chen is a professor and deputy director of the Shanghai Institute of Ceramics at the Chinese Academy of Sciences. He graduated with a degree in chemistry engineering at Hunan University, China, in 1981, and received his $\mathrm{PhD}$ degree in materials science from Tohoku University, Japan, in 1990. Chen worked primarily on advanced ceramics until 1996. Afterward, he

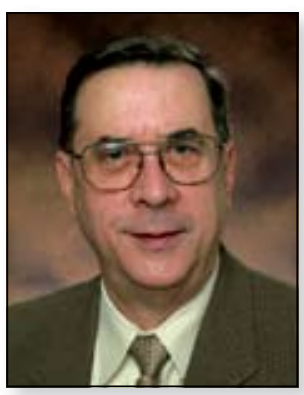

Joseph A. Carpenter, Jr.

started activities in thermoelectrics. Chen's current research activities are focused on the exploration of new thermoelectric compounds and nano-composite materials and on developing thermoelectric device technology.

Russell R. Chianelli can

be reached at The

University of Texas at

El Paso, 300 Burges Hall,

El Paso, TX 79968-0555,

USA; tel. 915-747-7555,

fax 915-747-6007, and

e-mail chianell@utep.edu.

Chianelli is a professor in the Department of Chemistry and director of the Materials Research and Technology Institute at The University of Texas at El Paso. He received his $\mathrm{PhD}$ degree in chemistry and physics from the Polytechnic Institute of Brooklyn in 1974. From 1973 to 1996, Chianelli was a senior research associate at Corporate Research Laboratories Exxon Research and Engineering $\mathrm{Co}$. He also was president of the Materials Research Society 1990 . In addition, he is currently the Texas Governor of the American Bio-fuels Council. Chianelli has authored more than 145 refereed publications and 55 U.S. patents.

Reuben T. Collins can be reached at the Physics Department, Colorado School of Mines, Golden, C0 80401, USA; tel. 303273-3851, fax 303-273-

3919, and e-mail rtcollin@ mines.edu.

Collins is a professor of physics and director of

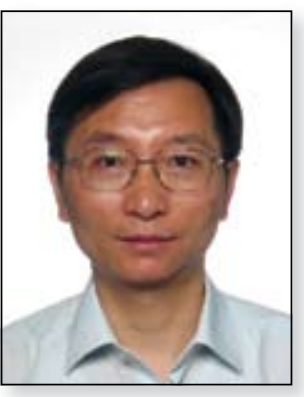

Lidong Chen

the Center for Solar and Electronic Materials at the Colorado School of Mines. He received a $B A$ degree in physics and mathematics from the University of Northern lowa in 1979, and $\mathrm{MS}$ and $\mathrm{PhD}$ degrees in applied physics from the California Institute of Technology in 1989 and 1985 , respectively. He held positions as research staff member, manager of III-V Epitaxy, and technical consultant to the vice president of services applications and solutions at IBM T.J. Watson Research before joining the Colorado School of Mines in 1994. Collins' research interests include photovoltaics, novel lightemitting materials and devices, microelectronics, silicon-compatible optoelectronics, fabrication and properties of nanostructures, and scanning probe microscopy. He has authored or co-authored more than 95 publications, is a co-inventor on three patents, and is a member of the American Physical Society,

Materials Research Society, and American Society for Engineering Educators.

Mildred S. Dresselhaus can be reached at Rm. 13-3005 Massachusetts Institute of Technology, 77 Massachusetts Ave. Cambridge, MA 021394307, USA; tel. 617-2536864, fax 617-253-6827, and e-mailmillie@mgm. mit.edu.

Dresselhaus is an institute professor of electrical engineering and

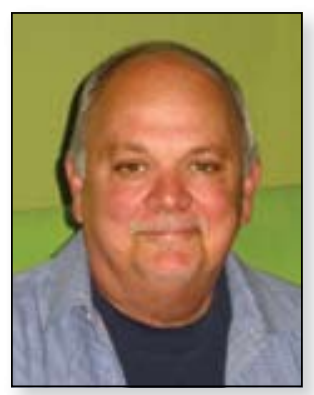

Russell R. Chianelli

physics at Massachusetts Institute of Technology.

She received her BS degree at Hunter College, her MA degree at Radcliffe College, and her PhD degree at the University of Chicago. At MIT,

Dresselhaus has worked broadly in solid-state physics, carbon science and its nanostructures, and low-dimensional thermoelectricity. She is the recipient of the National Medal of Science and 24 honorary degrees worldwide, and served as the director of the Office of Science at the Department of Energy in 2000-2001.

James Evans can be reached at 316 Hearst Mining Memorial BIdg., MS 1760, University of California at Berkeley, Berkeley, CA 94720, USA; tel. 510-642-3807, and e-mail evans@berkeley.edu.

Evans holds the Plato

Malozemoff Endowed chair in the Department of Materials Science and

Engineering at the

University of California at

Berkeley. His recent research has focused on electrochemistry, particularly as applied to materials production and energy storage. Evans has published approximately 180 papers in refereed archival journals (plus 120 other publications), has co-authored three books, and is a co-inventor on eight issued patents, including four related to batteries/fuel cells.

Rodney C. Ewing can be reached at University of Michigan, Department of

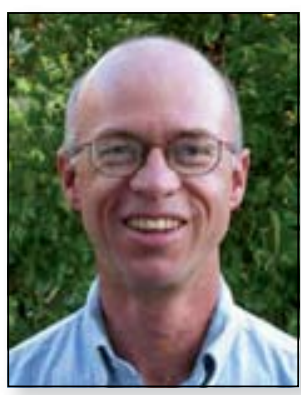

Reuben T. Collins

Geological Sciences, 1100 N. University Ave., Ann Arbor, Ml 48109-1005 USA; tel. 734-763-9295, fax 734-647-5706, and e-mail rodewing@umich. edu.

Ewing is the Donald $\mathrm{R}$. Peacor Collegiate Professor in the Department of Geological Sciences at the University of Michigan. He also is a professor in the

Departments of Nuclear Engineering and

Radiological Sciences and Materials Science and Engineering. Ewing's research interests focus on radiation effects in minerals, ion beam modification of materials, and the crystal-chemistry of actinide minerals and compounds. He is past president of the Mineralogical Society of America and the International Union of Materials Research Societies. Ewing has written extensively on issues related to nuclear waste management and is a co-editor of Radioactive Waste Forms for the Future (1988) and Uncertainty Underground (2006). He has received the Dana Medal of the Mineralogical Society of America and the Lomonosov Medal of the Russian Academy of Sciences.

Alexander E. Farrell can be reached at University of California at Berkeley, 310 Barrows Hall, Berkeley, CA 94720-3050, USA; tel. 510-642-1640, and e-mail aef@berkeley.edu.

Farrell is an associate professor in the Energy and Resources Group at the University of California at Berkeley and director of 


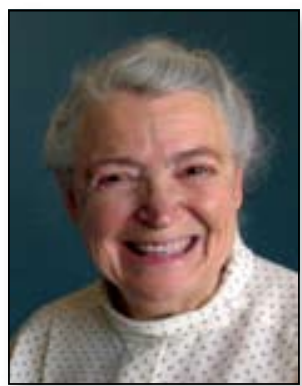

Mildred S. Dresselhaus

the Transportation

Sustainability Research

Center. He has a degree in systems engineering from the U.S. Naval Academy, and a $\mathrm{PhD}$ degree in energy management and policy from the University of Pennsylvania. Alex conducts research on energy and environmental policy, especially related to biofuels, climate change, security, and international environmental assessments and agreements.

Bruce C. Gates can be reached at the Department of Chemical Engineering and Materials Science, University of California at Davis, 1 Shields Ave., Davis, CA 95616-5294 USA; tel. 530-752-3953, fax 530-752-1031, and e-mail bcgates@ucdavis. edu.

Gates is a distinguished professor in chemical engineering and materials science at the University of California at Davis. He received degrees from the University of California at Berkeley in 1961 and the University of Washington in 1966. Gates worked at Chevron, following time spent as a postdoctoral researcher at the University of Munich, where he has returned frequently. Before joining the University of California at Davis, he was a professor and director of the Center for Catalytic

Science and Technology at the University of

Delaware. Gates' research is focused on catalysis. He has authored Catalytic Chemistry and coauthored Chemistry of Catalytic Processes. In

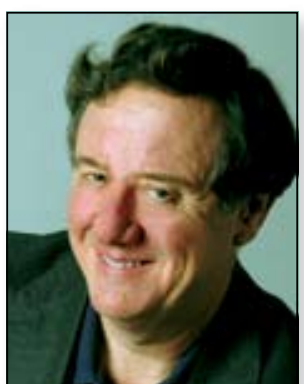

James Evans

addition, Gates edits

Advances in Catalysis.

Jerry Gibbs can be reached at the Office of

FreedomCAR and Vehicle Technologies, EE-2G Rm. 5G-046, U.S. Department of Energy, 1000 Independence Ave., SW, Washington, DC 20585, USA; tel. 202-5861182, and e-mail Jerry. gibbs@ee.doe.gov.

Gibbs is a technology development manager and materials engineer with the U.S. Department of Energy, Energy Efficiency and Renewable Energy, Office of Vehicle Technologies, Propulsion Materials. He has a BS degree in mechanical engineering from the University of Arizona in Tucson, AZ. Gibbs has more than 14 years of project management and field experience working with heavy- and light-duty vehicle systems utilizing both conventiona and alternative fuels.

\section{Dolf Gielen can be} reached at International Energy Agency, 9 Rue de la Federation, 75739 Paris Cedex 15, France; tel. +331-40-57-66-57, fax +33-140-57-67-59, and e-mail Dolf.Gielen@iea.org.

Gielen has been a senior energy analyst working for the International Energy Agency (IEA) in Paris in the Energy Technology Policy Division since 2002. Gielen studied chemical engineering at the Technical University Eindhoven and environmental sciences at Utrecht University in the Netherlands. In 1999, he finished his $\mathrm{PhD}$ degree

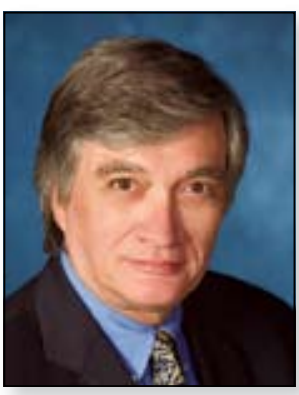

Rodney C. Ewing

thesis on energy and materials systems analysis at the Technical University Delft. Gielen's main task at IEA is to advise the IEA member governments regarding energy technology policies. He is currently coordinating the IEA activities in the field of industrial energy use in the framework of the G8 Dialogue on Climate Change, Clean Energy, and Sustainable Development. Also, Gielen is responsible for the energy technology modeling activities.

Anand R. Gopal can be reached at University of California at Berkeley, 310 Barrows Hall, Berkeley, CA 94720-3050, USA; tel. 510-642-1640, and e-mail anandrg@berkeley.edu.

Gopal is a PhD degree student in the Energy and Resources Group at the University of California at Berkeley. He has a master's degree in environmental systems engineering from Humboldt State University and a bachelor's degree in civil engineering from the Indian Institute of

Technology, Madras.

Gopal's research interests are in the area of energy technology and policy to meet developmental and environmental goals. Specifically for his $\mathrm{PhD}$ degree research, Gopal is exploring the potential of biomass power and biofuels to be a lowcarbon pathway to fulfill India's growing energy demand.

Martin A. Green can

be reached at ARC Photovoltaics Centre of

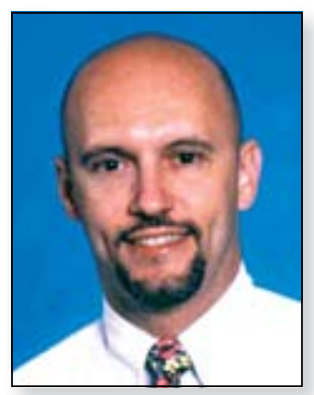

Alexander E. Farrell

Excellence, School of Photovoltaic and

Renewable Energy

Engineering, University of New South Wales, Sydney NSW 2052, Australia; tel.

+61-2-9385-4018, fax

+61-2-9662-4240, and

e-mailm.green@unsw. edu.au.

Green is currently an Australian Government Federation fellow, a scientia professor at the University of New South Wales, Sydney, Australia, and research director of the university's

Photovoltaic Centre of Excellence. His group's contributions to photovoltaics include development of the world's highest efficiency silicon solar cells and commercialization of several cell technologies. Green is the author of six books on solar cells and numerous papers. His work has resulted in several international awards including the 2002 Right Livelihood Award, commonly known as the Alternative Nobel Prize, and the 2007 SolarWorld Einstein Award.

Devens Gust can be reached at the Department of Chemistry and Biochemistry, PO Box 871604, Arizona State University, Tempe, AZ 85287-1604, USA; tel. 480-965-4547, fax 480965-2747, and e-mail gust@asu.edu.

Gust is the Foundation Professor of Chemistry and Biochemistry in the Department of Chemistry and Biochemistry at Arizona State University. He received his BS degree in chemistry from Stanford University,

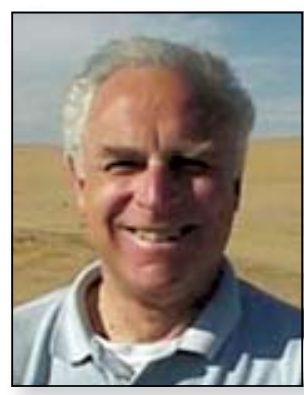

Bruce C. Gates

and his MS and $\mathrm{PhD}$ degrees in chemistry from Princeton University. Gust joined the faculty at Arizona State after postdoctoral research at the California Institute of Technology. His research is in the area of organic photochemistry with an emphasis in artificial photosynthesis and photochemical molecular logic. Gust received the Award in Photochemistry from the Inter-American Photochemical Society, and is a fellow of the American Association for the Advancement of Science.

Brian Hayman can be reached at Section for Structural Integrity and Laboratories, Det Norske Veritas AS, NO-1322 Høvik, Norway; tel. +4767-57-74-17, fax +47-6757-99-11, and e-mail Brian.Hayman@dnv.com.

Hayman is a senior principal engineer in the Section for Structural Integrity and Laboratories at Det Norske Veritas in Oslo. He received his $\mathrm{PhD}$ degree in structural engineering at University College London in 1970. Hayman joined Det Norske Veritas in 1984 $\mathrm{He}$ also is an adjunct professor of mechanics in the Department of Mathematics at the University of Oslo, and assists with teaching and supervision at the Technical University of Denmark. Hayman has extensive experience with research and consultancy services in ship and offshore structures. Recently, he has been responsible for a series of research projects 


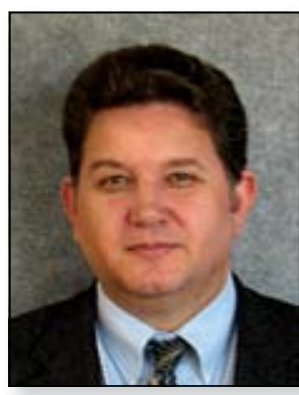

Jerry Gibbs

concerning material, structural, and joining technologies, with emphasis on lightweight structures-particularly sandwich composites.

Siegfried S. Hecker can be reached at the Center for International Security and Cooperation, Encina Hall, C-220, Stanford University, Stanford, CA 94305, USA; tel. 650-7256468, and e-mail

shecker@stanford.edu.

Hecker is co-director of the Center for

International Security and Cooperation, a senior fellow of the Freeman Spogli Institute for International Studies, and a research professor in the Department of Management Science and Engineering at Stanford University. In addition, Hecker is director emeritus at the Los Alamos National Laboratory. Hecker holds $\mathrm{BS}, \mathrm{MS}$, and $\mathrm{PhD}$ degrees in metallurgy from Case

Western Reserve University. His research interests include plutonium and actinide science, nuclear weapons, energy, nonproliferation and terrorism, and issues of international security. $\mathrm{He}$ is a member of the National Academy of Engineering, a foreign member of the Russian Academy of Sciences, and a fellow of TMS, ASM International, AAAS, and the American Academy of Arts and Sciences.

Stephen A. Holditch can be reached at Department of Petroleum Engineering,

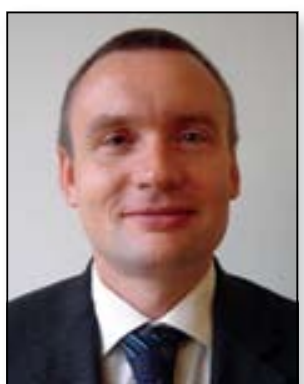

Dolf Gielen

Texas A\&M University, 3116 TAMU—507

Richardson Bldg., College Station, TX 77843-3116, USA; tel. 979-845-2255, and e-mail steve.

holditch@pe.tamu.edu.

Holditch is the head of the Petroleum Engineering Department at Texas A\&M University. From 1999 to 2003 ,

Holditch was a

Schlumberger Fellow,

where he was a

production and reservoir engineering advisor to the top managers within Schlumberger. Holditch was president of S.A. Holditch and Associates, Inc. from 1977 to 1999. In addition, Holditch was SPE president in 2002 and he was SPE vice president of finance from 1998 to 2000. As an SPE Officer, Holditch served on the SPE Board of Directors from 1998 to 2003. Holditch also served as an AIME Trustee from 1997 to 1998. In 1995, he was elected to the U.S. National Academy of Engineering (NAE), and in 2006, he was elected as an honorary member of SPE and AIME. Holditch has published more than 150 technical papers.

George W. Huber can be reached at the Department of Chemical Engineering, University of

Massachusetts-Amherst, 159 Goessmann Lab, 686 North Pleasant St., Amherst MA 01003-9303, USA; tel. 413-545-0276, fax 413545-1647, and e-mail huber@ecs.umass.edu.

Huber is the Armstrong Professional Development Professor of Chemical

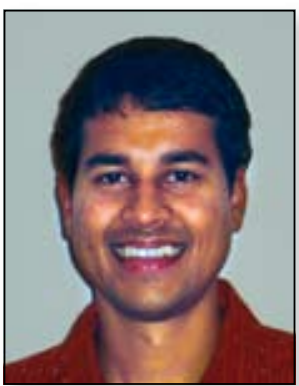

Anand R. Gopal

Engineering at University of Massachusetts-

Amherst. He received his $\mathrm{PhD}$ degree in chemical engineering from the University of Wisconsin-

Madison under the guidance of James A. Dumesic. Huber received his MS (directed by Calvin Bartholomew) and BS degrees in chemical engineering from Brigham Young University. After receiving his $\mathrm{PhD}$ degree, Huber was a postdoctoral researcher with Avelino Corma at the Universidad de Valencia, Spain. Huber's research focus is on breaking the chemical and engineering barriers to lignocellulosic biofuels. He has authored 25 peerreviewed publications, including two papers in Science.

Ron Judkoff can be reached at the Buildings and Thermal Systems Center, National Renewable Energy Laboratory, 1617 Cole Blvd., Golden, CO 80401, USA; tel. 303-3847520, fax 303-384-7540, and e-mail ron_judkoff@ nrel.gov.

Judkoff directs the Buildings and Thermal Systems Center at the National Renewable Energy Laboratory (NREL). Previously, he was a senior architectural engineer in the NREL Buildings research and development program, specializing in the energy design of highly efficient architecture and in simulation and monitoring techniques. Judkoff leads an International Energy Agency multinational task on developing validation methods for building

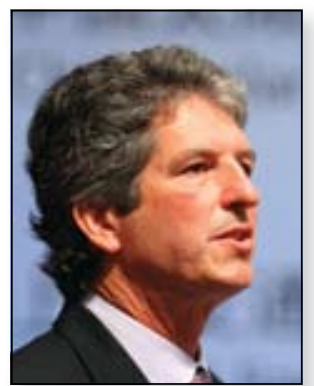

Martin A. Green

energy simulation software, and he is the author of a section in the ASHRAE Handbook of fundamentals on "Model Validation and Testing."

His work has been translated into numerous foreign languages, including Japanese, German, French, Dutch, and Portuguese, and has been cited in the building energy codes of the USA, Canada, Australia,

New Zealand, and many European countries. Judkoff has published more than 100 papers in peer-reviewed and popular literature. He also holds a patent on an apparatus for protecting building occupants from chemical and bio-aerosol attacks and a copyright for SUNREL Building Energy Simulation Software. Judkoff received his master's degree in architecture from Columbia University. His awards include the R\&D 100 Award in 2005 for development of the TREAT with SUNREL simulation software, in collaboration with New York State ERDA. Judkoff also has received the 2001 AlA Committee on the Environment Top Ten Green Building Award for energy design of the Zion National Park Visitor Center; the ASHRAE Technology Award, first place, in 1999 for energy design of the NREL TTF lab building; and the 1991 Federal

Laboratory Consortium Award for developing a calorimetric method to rapidly evaluate the thermal performance of manufactured buildings, thereby achieving a five-fold increase in the cost

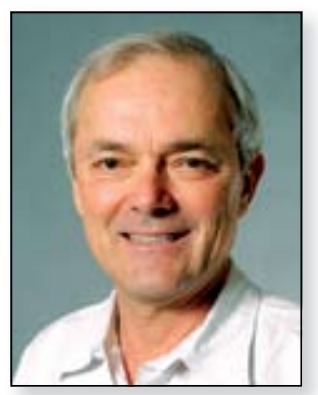

Devens Gust

effectiveness of retrofits for the National Low-Income Weatherization Program.

Kenneth Kelly can be reached at National Renewable Energy Laboratory, 1617 Cole Blvd., Golden, C0 80401, USA; tel. 303-275-4465, fax 303-275-4415, and e-mail kenneth_kelly@nrel.gov.

Kelly is a senior research engineer at the National Renewable Energy Laboratory (NREL) in Golden, CO. Kelly holds MS and $\mathrm{BS}$ degrees in mechanical engineering from Ohio University. Before joining NREL, he worked in industry as a manufacturing engineer with Swagelok Company. Kelly joined NREL in 1991 , where he is the task leade for research and development of advanced thermal control technologies for automotive power electronics. While at NREL, he also led efforts in Robust Design - for fuel cells and advanced heavyduty hybrid electric vehicles. Kelly also has experience with alternative fuel vehicle emissions testing and fleet evaluations

David M. Kramer can be reached at the Institute of Biological Chemistry, P0 Box 646340, Washington State University, Pullman, WA 99164-6340, USA; tel. 509-335-4964, and e-mail dkramer@wsu.edu.

Kramer is a professor and fellow of the Institute of Biological Chemistry, and chair of the Graduate Program in Molecular Plant Sciences at Washington 


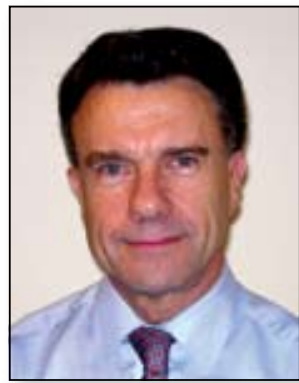

Brian Hayman

State University (WSU). He received his $\mathrm{PhD}$ degree in biophysics from University of Illinois at Urbana-Champaign, where he studied photosynthesis with Antony R. Crofts. Kramer joined WSU after spending time as a postdoctoral researcher at the Institut de Biologie Physico-Chimique in Paris, where he studied photosynthesis with Pierre Joliot. Kramer's current research focuses on how photosynthesis is integrated into the plant to supply energy, but does not produce deleterious side reactions.

Tetsuo Kusakabe can be reached at Kameyama Environmental and Industrial Safety Center AVC LCD Group, Sharp Corporation, 464,

Kougawa, Shiraki-cho, Kameyama-shi, Mie

Prefecture 519-0198, Japan; tel. +81-595-84-

1603, fax +81-595-84-

1729, and e-mail kusakabe.

tetsuo@sharp.co.jp.

Kusakabe is general manager at Kameyama Environmental and Industrial Safety Center, AVC LCD Group, at the Sharp Corporation in Japan. He joined Sharp in March, 1965. Kusakabe is engaged in establishing new Sharp bases in Japan. For the Kameyama Plant, he worked in cooperation with local governments and related businesses from the site-selection stage and contributed to improving the brand image by making the facility an environmentally advanced plant through the introduction of state-of-the-art environmental technologies.

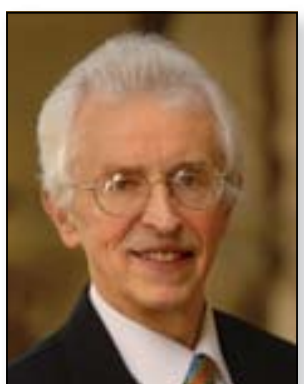

Siegfried S. Hecker

Lester Lave can be reached at the Department of Engineering and Public Policy, Carnegie Mellon University, Baker Hall 129, Pittsburgh, PA 15213, USA; tel. 412-2688837, fax 412-268-7357, and e-mail lave@cmu.edu.

Lave is a university professor and Higgins Professor of Economics at Carnegie Mellon University, with appointments in the business school,

engineering school, and the public policy school. He has a BA degree from Reed College and a PhD degree from Harvard University. Lave has been on the faculty of Carnegie Mellon since 1963. He also spent a year as a visiting professor at Northwestern University and four years as a senior fellow at the Brookings Institution. Lave is the founder and director of Carnegie Mellon's Green Design Institute, which has conducted research on sustainability, life-cycle analysis, and related topics for 15 years. In addition, he and Granger Morgan direct the Carnegie Mellon Electricity Industry Center-the largest engineering-business center focused on the electricity industry. Lave was elected to the Institute of Medicine of the National Academy of Sciences and is a past president of the Society for Risk Analysis. He has acted as a consultant to many government agencies and companies. Lave also has received research support from a wide range of federal and state agencies, as well as foundations, nongovernmental organizations, and companies.

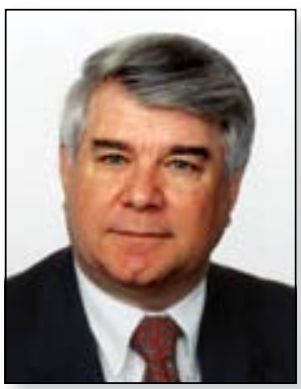

Stephen A. Holditch

Laura Marlino can be reached at the National Transportation Research Center at Oak Ridge National Laboratory, 2360 Cherahala Blvd., Knoxville, TN 379326472, USA; and e-mail marlinold@ornl.gov.

Marlino is the technical program manager overseeing the Power Electronics and Electric Machinery efforts at the Oak Ridge National Laboratory for the Department of Energy's (DOE) FreedomCAR effort. She received her BS degree in electronics engineering from the University of New Mexico in Albuquerque, and her MS degree in electronics engineering from the University of Tennessee in Knoxville. Prior to her current position, Marlino spent 10 years as a research engineer in the Power Electronics and Electric Machinery Research Center at the Oak Ridge National Laboratory. During her engineering career, she has been employed with Teledyne Camera Systems in California, performing analog video design; and Honeywell Aerospace and Marine in New Mexico, where she worked as a test and design engineer, involved with cockpit displays and processors for military aircraft. Marlino also has worked as a frontend IC design engineer with ASIC International in Oak Ridge, Tennessee. As part of her current responsibilities, Marlino oversees the technical progress on research and development efforts for hybrid, plug-in hybrid, and fuel-cell vehicle technology developments. For the past

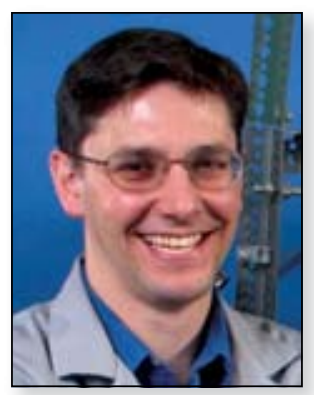

George W. Huber

five years, Marlino has been performing program and project management duties under the DOE's

Office of Vehicle Technologies Program. She also is a member of the Electrical and Electronics Technical Team within the United States Council for Automotive Research. Marlino holds four patents and has authored numerous technical publications.

Christopher L. Marshall

can be reached at Chemical Sciences \& Engineering Division, Argonne National Laboratory, 9700 S. Cass Ave., Bldg. 205, Argonne, IL 60439-95616, USA; tel. 630-252-4310, fax 630972-4408, and e-mail marshall@anl.gov.

Marshall is group leader for heterogeneous catalysis in the Chemical Sciences \& Engineering Division at Argonne National Laboratory. He received a BS degree from the State University of New York at Potsdam in 1975 , and $\mathrm{MS}$ and $\mathrm{PhD}$ degrees in inorganic chemistry from Michigan State University in 1977 and 1980, respectively. Before joining Argonne, he was employed in the

Exploratory and Catalysis Department at Amoco Oil Company R\&D

Department. The focus of his research is the fundamental chemistry of catalytic processes, particularly the use of in situ spectroscopic characterization.

Mark Mehos can be reached at the National

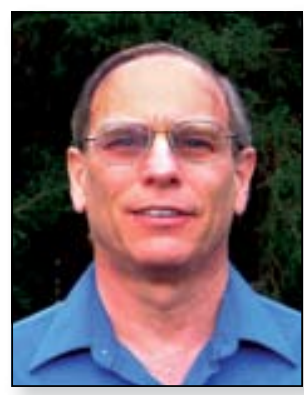

Ron Judkoff

Renewable Energy Laboratory, MS 1725 ,

1617 Cole Blvd., Golden, C0 80401, USA; tel. 303384-7458, fax 303-3847495, and e-mail

mark_mehos@nrel.gov.

Mehos is the program

manager of the

Concentrating Solar

Power Program at the

National Renewable

Energy Laboratory. Mehos earned his MS degree in mechanical engineering from the University of California at Berkeley and his BS degree in mechanical engineering from the University of Colorado. He has been with NREL since 1986. In addition to his work with the Concentrating Solar Power Program, Mehos leads NREL's HighTemperature Thermal Team, which focuses on developing low-cost, highperformance, highreliability systems using concentrated sunlight to generate powerparticularly large multimegawatt parabolic trough systems and kilowatt-scale concentrating photovoltaic systems. Mehos also participated in New Mexico Governor Bill Richardson's

Concentrating Solar

Power Task Force, and in the Solar Task Force for the Western Governors' Association Clean and Diversified Energy Initiative. His interests include advanced optical materials, solar 


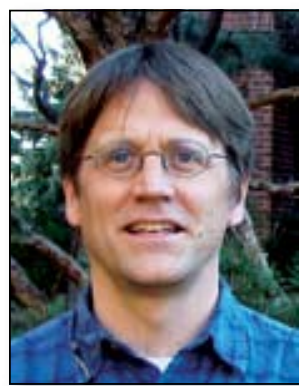

Kenneth Kelly

Biochemistry, PO Box 871604, Arizona State University, Tempe, AZ 85287-1604, USA; tel. 480-965-2953, fax 480965-2747, and e-mail

amoore@asu.edu.

Moore is a professor of chemistry and biochemistry at Arizona State University. She received her PhD degree from Texas Tech University and was a visiting scientist at the Muséum National d'Histoire Naturelle in Paris, the Laboratoire de Physico-Chimie des Systémes Polyphases (associated with the CNRS, Montepellier), and at the CEA Saclay in France. At Arizona State, Moore teaches undergraduate and graduate courses in organic chemistry, and her research interests are in the design and construction of bioinspired systems to carry out solar-energy conversion. Moore has served and on the council of the American Society for Photobiology and on the editorial advisory board of Accounts of Chemical Research, and is a council member of the International Society for Photobiology.

Thomas Moore can be reached at the Department of Chemistry and Biochemistry, PO Box 871604, Arizona State University, Tempe, AZ 85287-1604, USA; tel. 480-965-3308, fax 480965-2747, and e-mail tmoore@asu.edu.

Moore is a professor of chemistry and biochemistry and interim director of the Center for Bioenergy and

Photosynthesis at Arizona

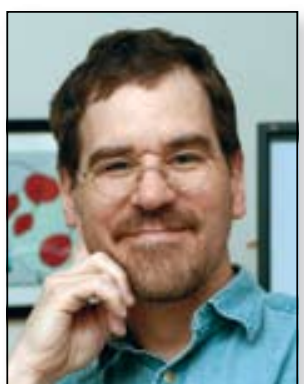

David M. Kramer

State University (ASU). He received his $\mathrm{PhD}$ degree in chemistry from Texas Tech University. Moore teaches undergraduate and graduate level biochemistry at ASU, and lectures in biophysics at the Universitè de Paris Sud, Orsay. His research in artificial photosynthesis is aimed at the design, synthesis, and assembly of bio-inspired constructs for sustainable energy production and efficient energy use. Moore was awarded a Chaire Internationale de

Recherche Blaise Pascal, Région d'lle de France, Service de Bioénergétique, CEA Saclay, France, for the period of 2005 to 2007 He has served as president of the American Society for Photobiology in 2004. and received the Senior Research Award from the Society in 2001.

Bryan D. Morreale can be reached at 626 Cochrans Mill Rd., P0 Box 618, Pittsburgh, PA 15236 USA; tel. 412-386-5929, fax 412-386-5920, and e-mail bryan.morreale@ netl.doe.gov.

Morreale is currently the research group leader for the Reaction Chemistry and Engineering Group of the Office of Research and Development at the US Department of Energy's National Energy Technology Laboratory. Morreale is an alumnus of the University of Pittsburgh, where he received his $\mathrm{PhD}$ degree from the Department of Chemical and Petroleum

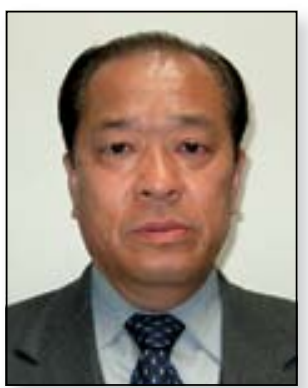

Tetsuo Kusakabe

Engineering and was the recipient of the annual Coull Memorial Award for Outstanding Graduate Student. His current research interests are focused on energy conversion and conservation technologies, specifically gasification, gas separations, synthesis gas conversion, and carbon utilization.

John Newman can be reached by e-mail at john. newman@iea.org.

Newman is an energy and environmental consultant to the International Energy Agency (IEA). Newman has a BS degree in metallurgical engineering from the Ohio State University and a MS degree in technology and policy studies from the Massachusetts Institute of Technology. Prior to becoming a consultant to IEA, Newman also held positions with the Organisation for Economic Cooperation and Development (OECD), working on basic science challenges in the energy sector; the IEA Secretariat, specializing in energy efficiency policy; the U.S. Office of Technology Assessment, analyzing industrial energy use and minerals policy; and the U.S. International Trade Commission, investigating steel trade issues.

Franklin M. Orr, Jr. can be reached at Stanford University, Global Climate and Energy Project, Yang and Yamasaki

Environment and Energy

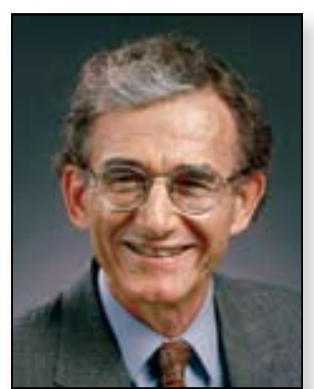

Lester Lave

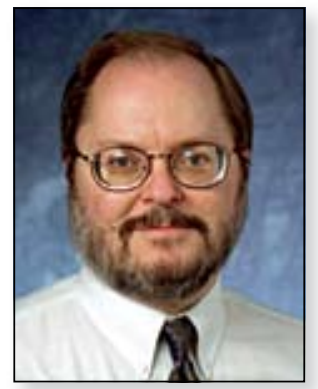

Christopher L. Marshall

Building, Rm. 324, 473 Via Ortega, Stanford, CA 94305-4230, USA; tel. 650-725-6270, fax 650725-9190, and e-mail fmorr@stanford.edu.

Orr is the Keleen and Carlton Beal Professor in Petroleum Engineering in the Department of Energy Resources Engineering and director of the Global Climate and Energy Project at Stanford University. He holds a $\mathrm{PhD}$ degree from the University of Minnesota and a BS degree from Stanford University, both in chemical engineering. Orr joined Stanford in 1985 and served as dean of the School of Earth Sciences from 1994 to 2002. His research interests include multiphase flow in porous media, $\mathrm{CO}_{2}$ sequestration, and reduction of greenhouse gas emissions from energy use. In addition, Orr is a member of the National Academy of Engineering.

Tim Palucka can be reached by e-mail at TPalucka@aol.com.

Palucka is the author of The 3 GW Initiative sidebar in this issue of MRS Bulletin.

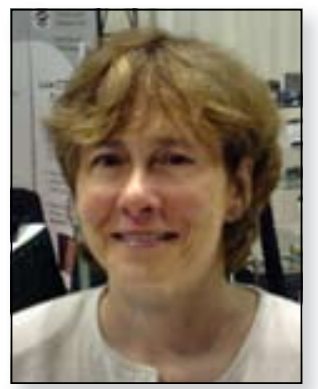

Laura Marlino

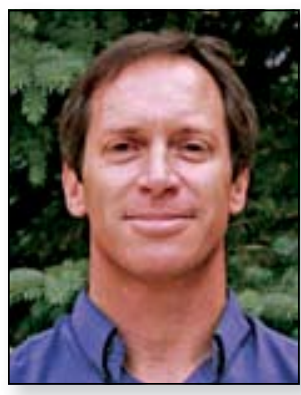

Mark Mehos

Martin K. Patel can be reached at the Department of Science, Technology and Society, Utrecht

University, Heidelberglaan 2, 3584 CS Utrecht, The

Netherlands; and e-mail m.k.patel@uu.nl.

Patel has been an assistant professor at the Department of Science, Technology, and Society (STS) at Utrecht University, Netherlands since 2001. Patel studied chemical engineering in Karlsruhe, Germany, and was with the Fraunhofer Institute ISI in Karlsruhe until 2000. He received his $\mathrm{PhD}$ degree from Utrecht University in 1999 for his thesis on the energy use and $\mathrm{CO}_{2}$ emissions, and the related saving potentials in the chemical sector. At STS, Patel is coordinating the research cluster "Energy and

Materials Demand and Efficiency." His work deals with the techno-economic analysis of energy saving, and emission reduction potentials in the industry sector, energy conversion, and waste management.

Ahmad Pesaran can be reached at National Renewable Energy Laboratory, 1617 Cole 


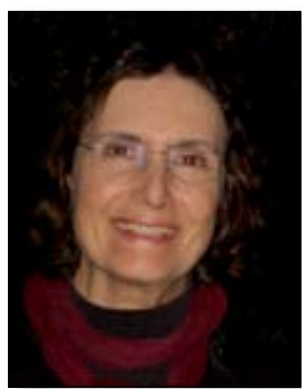

Ana Moore

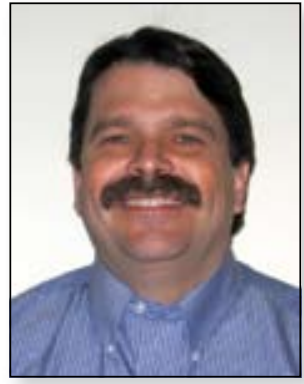

Tim Palucka

Blvd., Golden, C0 80401

USA; tel. 303-275-4441,

and e-mail ahmad

pesaran@nrel.gov.

Pesaran has worked at

the National Renewable

Energy Laboratory since

1983 in various energy

efficiency technologies in

building, advanced air

conditioning, and

automotive batteries. He

holds a $\mathrm{PhD}$ degree in

mechanical engineering

from University of

California, Los Angeles.

Pesaran started working on batteries, hybrid electric,

and fuel-cell vehicles in

1995, collaborating with

car and battery manufac-

turers on battery thermal

analysis and battery-pack

thermal management

issues as part of the U.S.

Department of Energy's

Vehicle Technologies

Programs. He currently

leads several projects for

the Department of Energy

and industrial partners,

which include thermal

characterization and

analysis of batteries,

modeling and simulation of

batteries, and ultracapaci-

tors for hybrid and plug-in

vehicles. He is an active

member of the

FreedomCAR

Electrochemical Energy

Storage Technical Team

and is a member of the

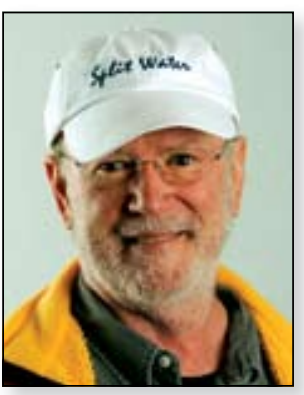

Thomas Moore

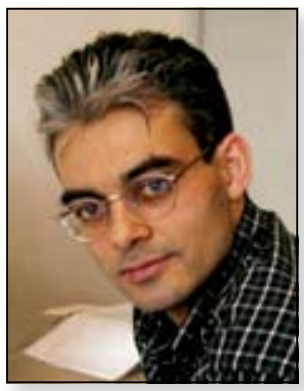

Martin K. Patel

Society of Automotive

Engineers and the

American Society of

Mechanical Engineers.

Cynthia A. Powell can be reached at Office of

Research and

Development, National

Energy Technology

Laboratory, 1450 Queen

Ave., SW, Albany, OR

97321, USA; tel. 541-967-

5803, fax 541-967-5914,

and e-mail cynthia.

powell@netl.doe.gov.

Powell is the Materials

Science Focus Area lead for the Office of Research and

Development at the US

Department of Energy's

National Energy

Technology Laboratory

(NETL). She received her

$\mathrm{PhD}$ degree in materials

science from Case Western

Reserve University in 1989,

preceded by MS and BS

degrees in ceramic

engineering from Clemson

University, in 1985 and

1983, respectively. Powell

has more than 15 years of

research experience in the areas of high-temperature phase and microstructural development in ceramic materials, particularly

refractories, and the

effect of these phase

changes on the bulk

properties of the material.

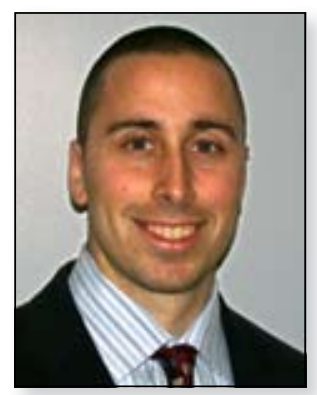

Bryan D. Morreale

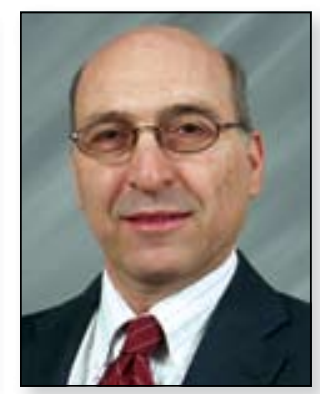

Ahmad Pesaran

At NETL, her research focuses on the development of improved performance materials that will enable the next generation of fossil-fuel power plants. Her research also has addressed microstructure/property and microstructure/ processing relationships in a wide range of intermetallic, metallic, and composite materials, and the influence of microstructure on the tribological performance of ceramics and ceramicbased composites. Powell has more than 40 publications in these areas. She also is listed as coinventor on a U.S. patent, which describes an improved material engineered for slagging gasifier applications.

Baldev Raj can be reached at Indira Gandhi Centre for Atomic

Research, Kalpakkam 603102, Tamil Nadu,

India; tel. +91-4427480240, fax +91-4427480060 , and e-mail secdmg@igcar.ernet.in, secdmg@igcar.gov.in or dir@igcar.gov.in.

Raj is a distinguished scientist and director of Indira Gandhi Centre for Atomic Research in

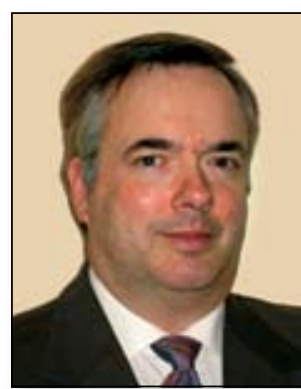

John Newman

Kalpakkam. Raj holds BE, $\mathrm{PhD}$, and $\mathrm{DSc}(\mathrm{hc})$ degrees. He has specialized in materials research and technology and fast reactor

technology and associated fuel cycle. In addition, his interests include technology management, heritage, philosophy, theosophy, and education. Raj has significant contributions in many national and international committees. He has more than 700 publications in journals, 12 books, five Indian standards, and 18 patents to his credit. Raj also has co-edited 28 books and special journal volumes. He is a recipient of the Padma Shri award from the Government of India. Raj is an active member of the Academy of Sciences in India and a fellow of the Third World Academy of Sciences.

\section{K. Bhanu Sankara Rao}

can be reached at Indira Gandhi Centre for Atomic

Research, Kalpakkam 603102, Tamil Nadu, India; tel. +91-44-

27480107, and e-mail bhanu@igcar.gov.in.

Rao is the associate director of the Materials Development and Characterisation Group at Indira Gandhi Centre for Atomic Research in Kalpakkam. He obtained his BE degree in metallurgical engineering in 1973, his MTech degree in physical metallurgy in 1975, and his $\mathrm{PhD}$ degree in metallurgical engineering in 1989. Rao has specialized in materials development and in the areas of creep, low-cycle fatigue, creep-fatigue interaction, life prediction,

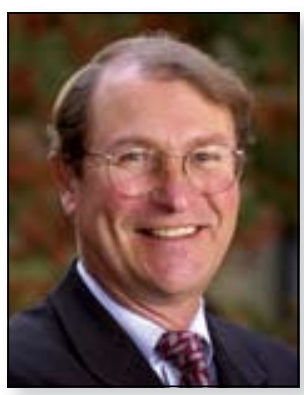

Franklin M. Orr, Jr.

and structure-property correlations. He is a fellow of ASM International, the Indian National Academy of Engineering, the Indian Academy of Sciences, and The Indian Institute of Metals. Rao also is currently the chief editor of Transactions of The Indian Institute of Metals and serves on the editorial board of International Materials Reviews.

P.R. Vasudeva Rao can be reached at Indira Gandhi Centre for Atomic

Research, Kalpakkam 603102, Tamil Nadu, India; tel. +91-4427480229, and e-mail vasu@igcar.gov.in.

Rao is currently heading the chemistry, metallurgy, and materials programs at the Indira Gandhi Centre for Atomic Research in Kalpakkam. A specialist in actinide separations, Rao has been working on various chemical aspects of fast reactor fuel cycles for more than 30 years. $\mathrm{He}$ also is an author of more than 150 publications in international journals.

Bhakta B. Rath can be reached at Materials

Science and Component Technology Directorate, Code 6000, Naval Research Laboratory, 4555 Overlook Ave., SW, Washington, DC 203755341, USA; tel. 202-7673566, fax 202-404-1207. e-mail rath@nrl.navy.mil, and www.nrl.navy.mil/ content.php?P=ADIR6000.

Rath is associate director of research and head of the Materials 


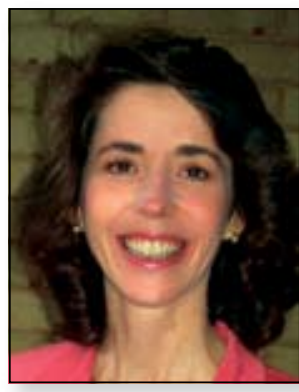

Cynthia A. Powell

Science and Component Technology Directorate at the Naval Research Laboratory in Washington, DC. He received a $\mathrm{PhD}$ degree from the Illinois Institute of Technology, an MS degree from the Michigan Technological University, and a BS degree from Utkal University in India. Rath's research interests include alternate energy resources and the behavior of materials. He served as the president of ASM International and has received numerous awards and honors, including the Distinguished Presidential Rank Award - the highest distinction presented to a senior executive of the U.S government-from President George W. Bush.

Philip N. Ross, Jr. can be reached at Materials Sciences Division,

Lawrence Berkeley National Laboratory, 1 Cyclotron

Rd., MS 66, Berkeley, CA 94720, USA; and e-mail

PNRoss@|bl.gov.

Ross recently retired from the Lawrence Berkeley National Laboratory of the University of California, where he was a senior scientist in the Materials Sciences Division and program leader of the electrochemical basic science program in the Environmental Energy Technologies Division. He received his BS degree in chemical engineering from Yale University in 1965 his MS degree in chemical engineering from the University of Delaware in 1969, and his PhD degree in engineering and applied science from Yale in 1973.

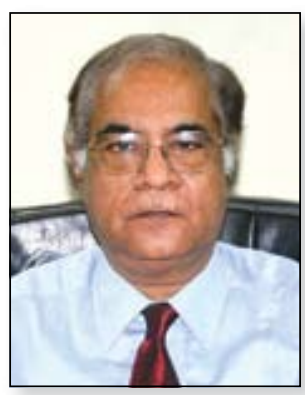

Baldev Ra

Ross worked at United Technologies Corporation before moving to Berkeley. His research has focused on fuel cell technologies, lithium batteries, and fundamental electrochemistry. Ross is co-editor of the Frontiers in

Electrochemistry series published by Wiley-VCH.

\section{Shad Roundy can be}

reached at LV Sensors, Inc., Hollis Business Center, 1480 64th St. Suite 175, Emeryville, CA 94608, USA; tel. 510-9033506, fax 510-903-3526, and e-mail sroundy@ Ivsensors.com.

Roundy is an architect of energy harvesting for LV Sensors. He received his $\mathrm{PhD}$ degree in mechanical engineering from University of California at Berkeley in 2003. Prior to his current position, Roundy was a lecturer at the Australian National University. His research interests include energy harvesting, smart materials, and MEMS. He has a particular interest in employing these technologies to applications that result in improved large-scale energy efficiency and conservation.

Jeffrey J. Siirola can be reached at Eastman Chemical Company, Kingsport, TN 376625150, USA; and e-mail siirola@eastman.com.

Jeff Siirola is a technology fellow at Eastman Chemical Company. His areas of interest include chemical process synthesis, process systems

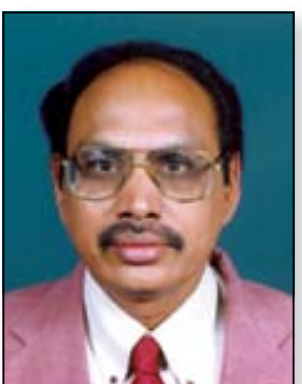

\section{K. Bhanu Sankara Rao}

engineering, technology assessment, resource conservation and recovery, sustainable development and growth, and chemical engineering education. He is a member of the National Academy of Engineering and was the 2005 president of the American Institute of Chemical Engineers.

Ralph E.H. Sims can be reached at the Renewable Energy Unit of the International Energy Agency, Paris, tel. +33-14051-6563. He remains director of the Centre for Energy Research, School of Engineering and Advanced Technology, College of Sciences, Private Bag 11222, Massey University, Palmerston North, New Zealand; tel. +64-63505288, fax +64-63505604, and e-mail R.E.Sims@massey.ac.nz.

Sims is professor of sustainable energy at Massey University, New Zealand. Over a 35-year career working in renewable energy, he has served on various boards, is a fellow of the NZ Institute of Professional Engineers, and a Companion of the Royal Society of New Zealand. Sims also was a lead author in the IPCC 3rd Assessment Report Mitigation (2001) and is the coordinating lead author for the energy supply chapter of the 4th Assessment Report (2007)

Wole Soboyejo can be reached at the Department of Mechanical and Aerospace Engineering,

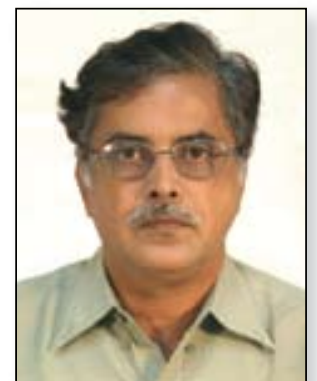

P.R. Vasudeva Rao

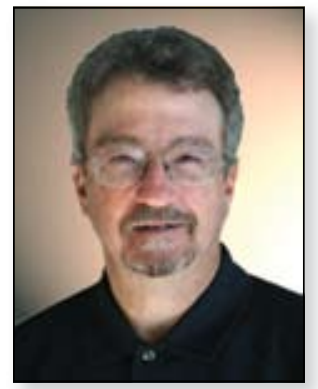

Philip N. Ross, Jr.

Princeton University, Olden St., Princeton, NJ 09544, USA; tel. 609-2585609, fax 609-258-5877. and e-mail soboyejo@ princeton.edu.

Soboyejo is a professor of materials in the Department of Mechanical and Aerospace Engineering, and the Princeton Institute of Science and Technology of Materials (PRISM) at Princeton University. He is also the director of the US/ Africa Materials Institute (USAMI) and the

Undergraduate Program in Materials at Princeton University. Soboyejo is chair of The African

Scientific Committee of The Nelson Mandela Institutions. He has spent approximately 10 years working on problems of solar energy for the poor. Soboyejo's efforts include research on organic electronics for photovoltaics and organic lightemitting devices, passive solar energy concept for thermal management of homes, and solar energy projects that provide alternative sustainable solutions.

Dan Steingart can be reached at 316 Hearst Mining Memorial BIdg.,

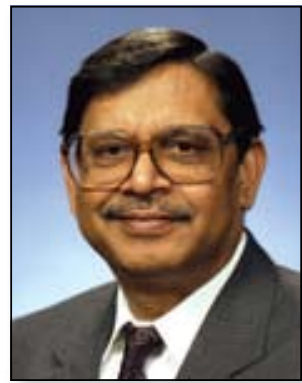

Bhakta B. Rath

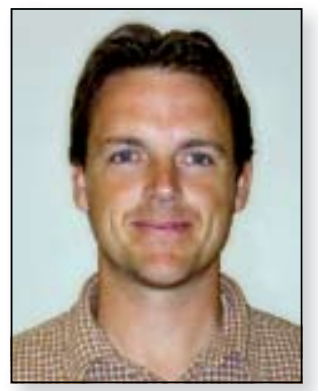

Shad Roundy

MS 1760, University of California at Berkeley, Berkeley, CA 94720, USA; and e-mail dan.steingart@ berkeley.edu.

Steingart is a lecturer and post-doctoral researcher at University of California at Berkeley, as well as co-founder and CTO of Wireless Industrial Technologies. He received his $\mathrm{PhD}$ degree in materials science and engineering in 2006 from UC Berkeley. Steingart's research interests include power generation, storage, and management for individual sensor nodes, as well as tailoring groups of nodes for industrial and environmental monitoring. He also is interested in minimal manufacturing through additive printing techniques.

John Stringer can be

reached by e-mail at jstringer@izambard.com.

He received his BEng, $\mathrm{PhD}$, and DEng degrees from the University of Liverpool in England. He was a lecturer in the Department of Metallurgy there from 1957 to 1962 . and following a brief period in the Metals Science Group at Battelle's 


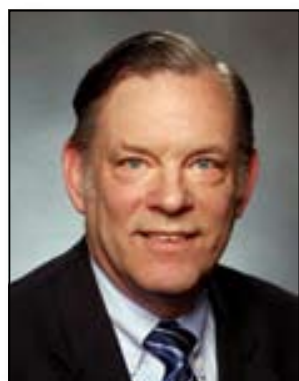

Jeffrey J. Siirola

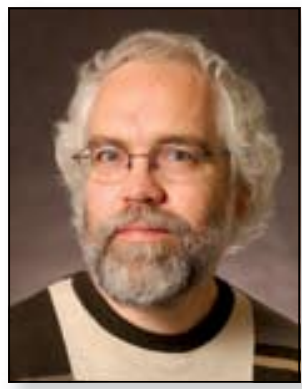

Wim Vermaas

Columbus Laboratories, he was appointed to the Chair of Materials Science at Liverpool. In 1977 he joined the Electric Power Research Institute in Palo Alto, California, remaing there until his retirement in 2004. He received a Chauncey Award from EPRI for his research in biomimetic approaches to $\mathrm{CO}_{2}$ sequestration in 2000 , and a Lifetime Achievement Award from EPRI in 2002. For much of his time at EPRI he was Executive Technical Fellow in charge of Exploratory Research. In addition, during the period 1977 to 1999 he was a Consulting Professor at Stanford University. He is a fellow of the American Association for the Advancement of Science, the Institute of Energy (U.K.), the Minerals, Metals, and Materials Society of AIME, ASM International, the National Association of Corrosion Engineers, and the Royal Society of Arts. In addition, he is honorary fellow of the Institute of Corrosion (U. K.) He is also a Chartered Engineer in the U.K. His personal research interests include high temperature oxidation of metals and alloys, high temperature materials, smart materials

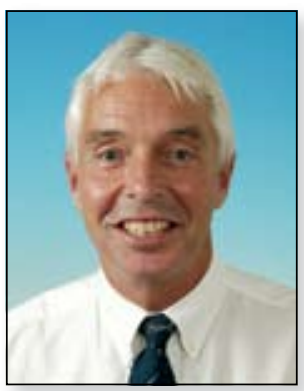

Ralph E.H. Sims

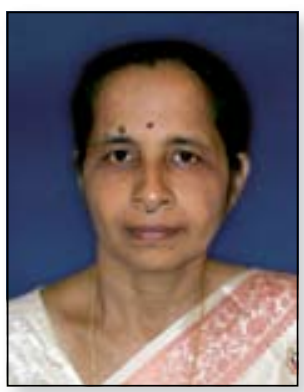

M. Vijayalakshmi

and structures, nanotechnology, biomimesis and biomimetic materials, and solid-state theory. He has received the Ulick R. Evans Award of the Institute of Corrosion (U.K.), the Campbell Memorial Lectureship of ASM International, and the Whitney Award of NACE International. He has participated in a number of advisory committees, in particular the National Materials Advisory Board and DOE's Basic Energy Science Advisory

Committee. He acted as Chairman of BESAC from 1996 to 1998 . He was a member of Panel 6, Materials for Fusion Reactors of DOE's Fusion Energy Advisory Committee, and a member of the University of Chicago Review Committee for the Chemical Technology Division of Argonne National Laboratory, 1987-1993; and Chair for his final two years. He has also been involved in a number of management committees within ASM, AIME, and NACE.

Roger Taylor can be reached at National Renewable Energy Laboratory, 1617 Cole

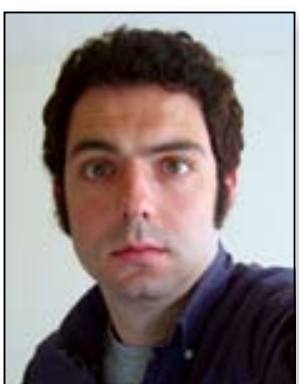

Dan Steingart

Blvd., Golden, C0 80401, USA; tel. 303-384-7389, fax 303-384-7419, e-mail roger_taylor@nrel.gov.

Taylor manages the State, Local and Tribal Integrated Applications Group at the U.S.

Department of Energy's National Renewable Energy Laboratory (NREL) in Golden, Colorado. Prior to his current position at NREL, Taylor spent a decade working in international rural development and six years working with Native American communities throughout the U.S. With 30 years of experience in renewable energy technology development and application, his quest has been to expand and promote the use of renewable energy to support sustainable economic development both domestically and internationally.

Terry M. Tritt can be reached at CU Complex Materials Laboratory, 118 Kinard Laboratory, Clemson University, Clemson, SC 296340978, USA; tel. 864-6565319, and e-mail ttritt@ clemson.edu.

Tritt is a professor of physics at Clemson University. The focus of the program is on electrical and thermal transport in new and novel materials, with current interests in materials for thermoelectric refrigeration and power generation applications.

Tritt is considered an international expert in the field of thermoelectric materials research. His primary research expertise lies in electrical and

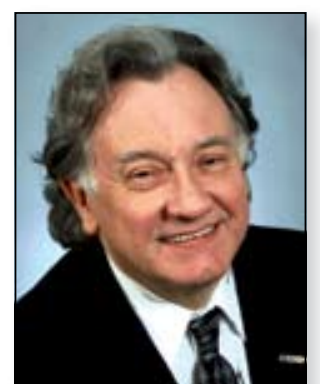

John Stringer

thermal transport properties and phenomena (especially in measurement and characterization techniques) in new and novel materials. In addition, Tritt has recently become involved in the synthesis and characterization of thermoelectric nanomaterials. He has extensive expertise in measurement science and has built an internationally known laboratory for the measurement and characterization of thermoelectric materials parameters, particularly thermal conductivity. Tritt has served as lead organizer of three Materials Research Society symposia on thermoelectrics materials (MRS Volumes 478, 545 and 626). Tritt will serve as an MRS Meeting Chair for the Spring 2009 Meeting. He has been a member of the executive board of the International

Thermoelectrics Society (ITS) since 1999, and served as chairman and host of the 24th ITC2005 at Clemson in June of 2005. Tritt has written more than 150 journal publications and regularly gives invited presentations at national and international meetings. He also was recently an author and lead editor of a MRS Bulletin theme (March 2006) on thermoelectric materials and devices. Tritt edited a three-volume set on "Recent Trends in Thermoelectric Materials Research" (Academic Press-2000) and has recently edited a book by Kluwer Press on thermal conductivity.

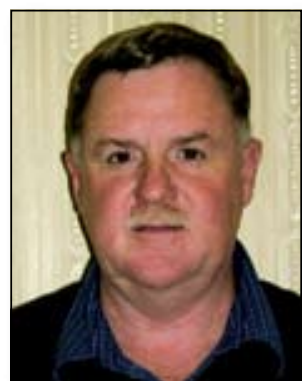

Terry M. Tritt

Wim Vermaas can be reached at the School of Life Sciences, Arizona State University, PO Box 874501, Tempe, AZ 85287-4501, USA; tel. 480-965-6250, fax 480965-6899, and e-mail wim@asu.edu.

Vermaas is a

professor in the School of

Life Sciences at Arizona

State University (ASU),

and is part of the Center

for Bioenergy and

Photosynthesis. He obtained his doctorate degree from the Agricultural University in Wageningen, The Netherlands, in 1984, and has been at ASU since 1986. Vermaas has been a driving force in setting up molecular tools for metabolic engineering of cyanobacteria, and his current research interests include design and utilization of cyanobacteria for improved biofuels production from sunlight, $\mathrm{CO}_{2}$, and water.

M. Vijayalakshmi can be reached at Indira Gandhi Centre for Atomic

Research, Kalpakkam 603102, Tamil Nadu, India; tel. +91-4427480306, and e-mail mvl@igcar.gov.in.

Vijayalakshmi is head of the Physical Metallurgy Division at Indira Gandhi Centre for Atomic Research in Kalpakkam. She has specialized in alloy development for nuclear industry, structure-property correlations, and phase transformations for nearly 30 years. Vijayalakshmi has published a book, chapters in several books and an encyclopedia, and 


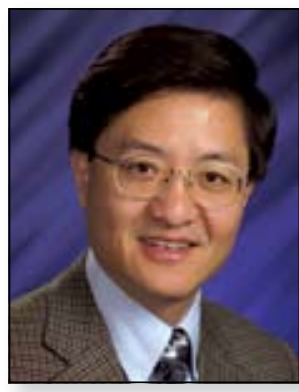

Yong Wang

original research papers She also has received a number of awards and is a fellow of The Indian Institute of Metals.

Yong Wang can be reached at the Chemical and Biological Process

Development Group,

Pacific Northwest

National Laboratory,

MSIN: K8-93, 902

Battelle Blvd., Richland,

WA 99354, USA; tel. 509-

376-5117, fax 509-376-

5106 , and e-mail

yongwang@pnl.gov.

Wang is a laboratory

fellow at Pacific Northwest

National Laboratory. He received his MS and PhD degrees in chemical engineering from

Washington State University in 1992 and

1993, respectively. Wang's research interests are in the development of novel catalytic materials and innovative reaction engineering for hydrocar-

bon and biomass

conversions. He is program

committee chair of the

American Chemical Society

Petroleum Division and

also serves on the editorial board of Catalysis Today.

Wang has approximately

100 publications and 50

U.S. patents. In addition, he won the 2006 Asian American Engineer of the Year award from the Chinese Institute of Engineers.

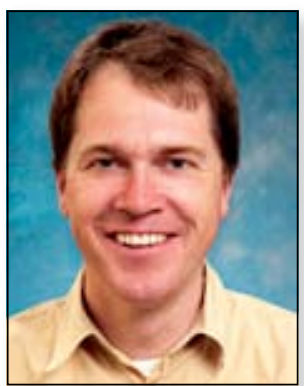

Jakob Wedel-Heinen

Jakob Wedel-Heinen can be reached at Det Norske Veritas, Danmark A/S, Tuborg Parkvej 8 , 2nd Floor, DK-2900 Hellerup, Denmark; tel. +45-39-45-48-54, fax +45-39-45-48-01, and e-mail jakob.wedelheinen@dnv.com.

Wedel-Heinen has worked at Det Norske Veritas in the certification of wind turbine blades for more than 15 years. He received his $\mathrm{PhD}$ degree from the Technical University of Denmark (DTU) in 1990. WedelHeinen then spent two years as a postdoctoral fellow at DTU, researching composite structures. Afterward, he joined Det Norske Veritas in 1992 to work with the certification of wind turbines and offshore structures.

\section{Stanley Whittingham}

can be reached at the Department of Chemistry and Materials, PO Box 6000 , State University of New York at Binghamton, Binghamton, NY 139026000 . USA; tel. and fax 607-777-4623, and e-mail stanwhit@gmail.com.

Whittingham is a professor of materials science and director of the Materials Science

Program and Institute for Materials Research at the State University of New York at Binghamton.

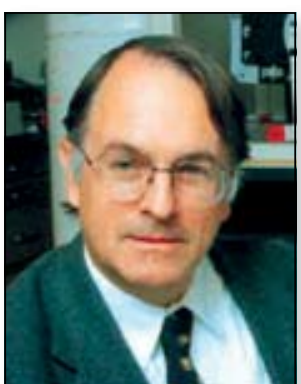

M. Stanley Whittingham

Whittingham received his $\mathrm{BA}$ and $\mathrm{PhD}$ degrees in chemistry from 0xford University, working with Peter Dickens. In 1968, he joined professor Robert $A$. Huggins' research group in the Materials Science Department at Stanford University as a postdoctoral research associate to study fast-ion transport in solids. In 1972

Whittingham joined Exxon Research and Engineering Company to initiate a program in alternative energy production and storage. After 16 years in industry, he joined the Binghamton campus of the State University of New York as a professor of chemistry to initiate an academic program in materials chemistry. His recent work focuses on the synthesis and characterization of novel microporous and nanooxides and phosphates for possible electrochemical and sensor applications. Whittingham was principal editor of the Journal Solid State lonics for 20 years. He also was elected a fellow of the

Electrochemical Society in 2004. In addition,

Whittingham was awarded the Young Author Award of the Electrochemical Society in 1971, a JSPS fellowship in the Physics Department of the University of Tokyo in 1993, and the Battery

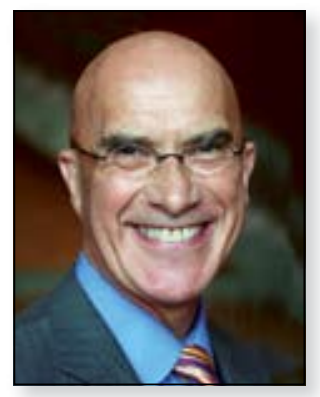

Paul Wright

Research Award of the Electrochemical Society in 2002.

\section{Paul Wright can be}

reached at 5133

Etcheverry Hall, MS 1740

University of California at

Berkeley, Berkeley, CA

94720-1740, USA; tel.

510-642-2527, and e-mail pwright@me.berkeley.edu.

Wright assumed the position of chief scientist for the Center for Information Technology Research in the Interest of Society (CITRIS) at

University of California at Berkeley in January 2006 and also is a professor in the mechanical engineering department, where he holds the A. Martin Berlin chair. Wright attended Birmingham and Cambridge Universities prior to previous faculty positions at New York University and Carnegie

Mellon University. Currently, he and his colleagues are designing and prototyping wireless systems for "demand response power management" throughout California, funded by Public Interest Energy Research (PIER) program of the California Energy Commission (CEC).

Charles E. Wyman can

be reached at the Center for Environmental

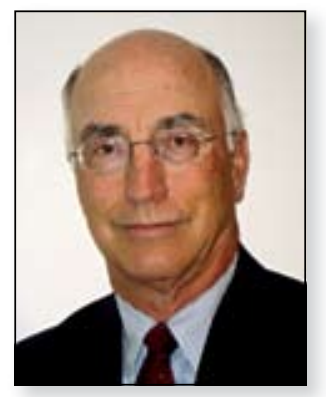

Charles E. Wyman

Research and

Technology, Bourns

College of Engineering,

University of California

at Riverside, 1084

Columbia Ave., Riverside,

CA 92507, USA;

tel. 951-781-5703, fax

951-781-5790, and

e-mail cewyman@engr. ucr.edu.

Wyman is currently the Ford Motor Company Chair in Environmental Engineering and Professor in the Chemical and Environmental

Engineering Department at the University of California at Riverside. $\mathrm{He}$ also is co-founder, chief development officer, and chair of the Scientific Advisory Board for Mascoma Corporation, a startup cellulosic ethanol company. Wyman holds a BS degree from the University of

Massachusetts and MA and $\mathrm{PhD}$ degrees from Princeton University, all in chemical engineering plus an MBA from the

University of Denver. He has devoted most of his career to leading advancement of biological conversion of cellulosic biomass to ethanol in academia, a government laboratory, and industry. In addition, Wyman has contributed numerous papers and book chapters, many presentations, and several patents.

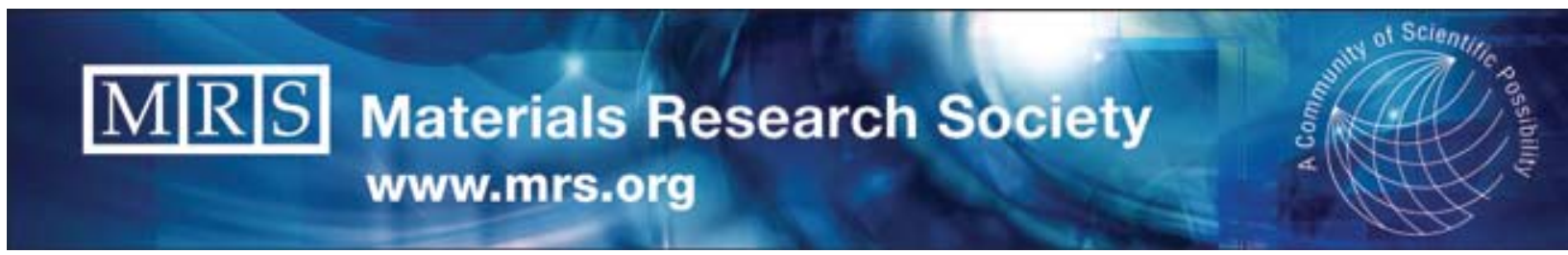


Twice the selection.

Stronger tech support.

Get everything you need...

Vacuum feedthroughs and manipulators of all kinds:

Rotary, linear, angular or X-Y-Z.

Coaxial or multimotion. Pneumatic, manual or motorized. With accessories for holding, transferring, heating, cooling...

Huntington offers more because they've designed more. And patented more. They can give you more intelligent answers because their engineers know positioners and how to solve your vacuum system problems.

And, they've got a lot more than positioners...

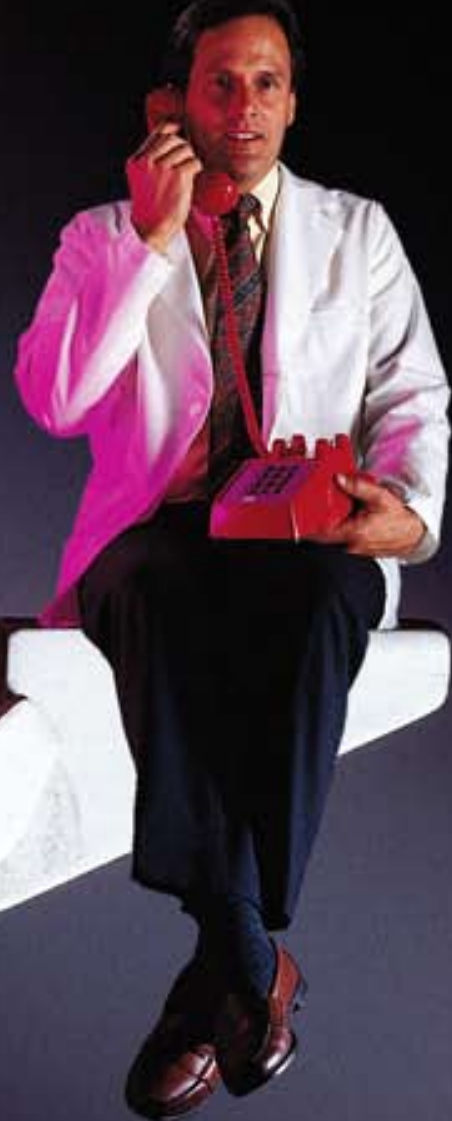

$\triangle$ VACUUM POSITIONERS, I TALK TO HUNTINGTON."
On the Web. On CD-ROM. In the big free catalog.

Huntington has it all: valves to connectors to chambers. Just check out Web site bitt:I//uww, bunttuac.com.

Or get Autodesk's Mecbanical Library on CD-ROM. And plug component drawings directly into your designs.

Or get the big new catalog: Just contact Huntington Laboratories, 1040 L'Avenida, Mountain View, CA 94043. (800) 227-8059 or (650) 964-3323. Fax: (650)964-6153.

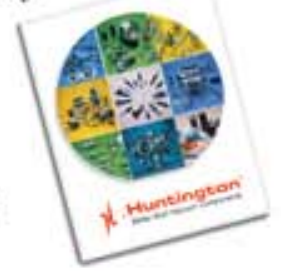
QP. Huntington 